\title{
Qualitative Rather than Quantitative Changes Are Hallmarks of Fibroblasts in Bleomycin-Induced Pulmonary Fibrosis
}

\author{
Tatsuya Tsukui, ${ }^{* \dagger}$ Satoshi Ueha, ${ }^{* \dagger}$ Jun Abe, ${ }^{* \dagger}$ Shin-ichi Hashimoto, ${ }^{* \dagger}$ Shigeyuki Shichino, ${ }^{* \dagger}$ Takeshi Shimaoka, ${ }^{* \dagger}$ \\ Francis H.W. Shand, ${ }^{\ddagger}$ Yasuka Arakawa, ${ }^{* \dagger}$ Kenshiro 0shima, ${ }^{\S}$ Masahira Hattori, ${ }^{\S}$ Yutaka Inagaki, ${ }^{\dagger \uparrow}$ Michio Tomura, and \\ Kouji Matsushima*†
}

\begin{abstract}
From the Department of Molecular Preventive Medicine,* Graduate School of Medicine, University of Tokyo, Tokyo, Japan; the Japan Science and Technology Agency-CREST Program, ${ }^{\dagger}$ Tokyo, Japan; the Department of Pharmacology, ${ }^{\ddagger}$ University of Melbourne, Parkville, Australia; the Department of Computational Biology, ${ }^{\S}$ Graduate School of Frontier Sciences, University of Tokyo, Chiba, Japan; the Research Unit for Tissue Remodeling and Regeneration, "Tokai University School of Medicine, Kanagawa, Japan; and the Center for Innovation in Immunoregulative Technology and Therapeutics, " Kyoto University Graduate School of Medicine, Kyoto, Japan
\end{abstract}

Accepted for publication

June 3, 2013.

Address correspondence to Kouji Matsushima, M.D., Ph.D., Department of Molecular Preventive Medicine, Graduate School of Medicine, The University of Tokyo, 7-3-1, Hongo, Bunkyo-ku, Tokyo 113-0033, Japan. E-mail: koujim@m.u-tokyo.ac.jp.

\begin{abstract}
Pulmonary fibrosis is characterized by accumulation of activated fibroblasts that produce excessive amounts of extracellular matrix components such as collagen type I. However, the dynamics and activation signatures of fibroblasts during fibrogenesis remain poorly understood, especially in vivo. We examined changes in lung tissue cell populations and in the phenotype of activated fibroblasts after acute injury in a model of bleomycin-induced pulmonary fibrosis. Despite clustering of collagen type Iproducing fibroblasts in fibrotic regions, flow cytometry-based quantitative analysis of whole lungs revealed that the number of fibroblasts in the lungs remained constant. At the peak of inflammation, fibroblast proliferation and apoptosis were both increased, suggesting that the clustering was not merely a result of proliferation, but also of fibroblast migration from nearby alveolar walls. Parabiosis experiments demonstrated that fibroblasts were not supplied from the circulation. Comprehensive gene expression analysis of freshly isolated fibroblasts revealed a detailed activation signature associated with fibrogenesis, including changes in genes responsible for migration and extracellular matrix construction. The Spp1 gene, which encodes osteopontin, was highly up-regulated and was an identifying characteristic of activated fibroblasts present at the sites of remodeling. Osteopontin may serve as a useful marker of profibrotic fibroblasts. These results provide insights into the cellular and molecular mechanisms underlying pulmonary fibrosis and provide a foundation for development of specific antifibrotic therapies. (Am J Pathol 2013, 183: 758-773; http://dx.doi.org/10.1016/j.ajpath.2013.06.005)
\end{abstract}

Fibrosis is a common pathological feature of chronic inflammation. In response to injury, activated fibroblasts accumulate in damaged tissue and irreversibly deposit excessive amounts of extracellular matrix (ECM) components, which severely impair organ function. ${ }^{1}$ In the lungs, the most common fibrotic disease is idiopathic pulmonary fibrosis, which is characterized by a histological pattern of usual interstitial pneumonia including bronchiolization and honeycombing. Because means for early diagnosis and effective therapies are lacking for idiopathic pulmonary fibrosis, patients have a median survival of only 2.5 to 3.5 years after diagnosis. ${ }^{2}$

Within fibrotic lesions, fibroblastic cells are activated by cytokines and growth factors such as TGF- $\beta$, often expressing $\alpha$-smooth muscle actin ( $\alpha$-SMA) and adopting a myofibroblast phenotype. As the major producers of ECM components such as collagen type I, myofibroblasts play a central role in the pathogenesis of fibrosis. ${ }^{3,4}$ Myofibroblasts derive from several types of progenitor cells, depending on the organ and experimental model. Although resident fibroblasts have been considered the major progenitors of myofibroblasts in the lungs, the extent of the contribution of other cell populations, such as epithelial cells or fibrocytes, remains a matter of debate. ${ }^{5-8}$ Hoyles et $\mathrm{al}^{9}$ found that resident fibroblast-specific deletion of the high-affinity type II TGF- $\beta$ receptor attenuated bleomycin-induced lung fibrosis,

Supported by the Japan Science and Technology Agency (CREST Program). 
demonstrating the important role of resident fibroblasts in their model. Rock et $\mathrm{al}^{10}$ recently used genetic lineage labeling to demonstrate that type II alveolar cells and Scgb1a1-positive cells (mainly bronchiolar Clara cells) in the alveoli and bronchioles did not become myofibroblasts through epithelial-to-mesenchymal transition in bleomycininduced lung fibrosis. They also showed that NG2-expressing pericyte-like cells (which are sources of myofibroblasts in some fibrosis models ${ }^{11,12}$ ) were not major progenitors of myofibroblasts in the lungs. Nonetheless, there remains a need to clarify the role of resident fibroblasts as myofibroblast progenitors in the lungs.

Resident fibroblasts, which comprise $30 \%$ to $40 \%$ of tissue cells in the lungs, form scaffolds for alveoli by secreting ECM components. ${ }^{13}$ Despite the prevalence of these cells in the alveoli and despite their postulated roles in pulmonary fibrosis, the in vivo properties of resident fibroblasts in both their normal and activated states remain poorly understood. Fibroblasts lack specific surface markers, and stromal cell heterogeneity in lung has not been well characterized. Earlier studies have often isolated fibroblasts by their adhesiveness to plastic dishes, which in itself can affect the phenotype of fibroblasts. ${ }^{14}$ In addition, the histological approaches that are commonly used in fibrosis studies have limited parameters and resolution for the quantitative analysis of single cells. For these reasons, it remains largely unknown how fibroblasts generate fibrotic lesions and contribute to organ fibrosis. To develop novel therapies for pulmonary fibrosis that specifically suppress fibroblast activation, accumulation, and ECM deposition, a more detailed picture of how these processes occur is required.

In the present study, we analyzed qualitative and quantitative changes in fibroblast populations in a model of bleomycin-induced lung fibrosis. Fibroblasts were identified using collagen type I, alpha 2 (Colla2) reporter mice, in which collagen type I-expressing fibroblasts are labeled with EGFP. ${ }^{15,16}$ Flow-cytometric analysis of cells from enzymatically dissociated lung tissue taken during bleomycininduced lung fibrosis revealed phenotypic changes without a change in overall fibroblast numbers. Although fibroblast proliferation increased, this was countered by a similar increase in apoptosis. On the other hand, gene expression profiles of freshly isolated fibroblasts generated by nextgeneration DNA sequencing revealed a detailed gene signature for profibrotic cells. Specifically, the gene encoding osteopontin (OPN) was highly up-regulated, suggesting that OPN may serve as an activation marker of lung fibroblasts.

\section{Materials and Methods}

Mice

Col1a2-GFP (C57BL/6 background for $\geq 10$ generations) and ROSA-CAG-SCAT3.1 mice were generated in previous studies. ${ }^{16,17}$ ROSA-CAG-SCAT3.1 mice were generated with BDF1-derived ES cells and backcrossed to C57BL/6 mice for at least two generations. ${ }^{17}$ The properties of FucciG1-\#639 and FucciS/G2/M-\#474 mice (both C57BL/6 background) are to be published elsewhere. C57BL6/J mice were purchased from Japan SLC (Hamamatsu, Japan) or CLEA Japan (Tokyo, Japan). Animal experiments were performed on 6- to 12-week-old mice. Mice were bred and maintained in specific pathogen-free facilities at the University of Tokyo. All animal experiments were performed in accordance with the guidelines of the Animal Care and Use Committee of the University of Tokyo.

\section{Intratracheal Instillation}

Mice were anesthetized with pentobarbital. Bleomycin sulfate $(1.25$ to $2.5 \mathrm{mg} / \mathrm{kg}$ dissolved in $50 \mu \mathrm{L}$ of saline solution; Toronto Research Chemical, Toronto, ON, Canada) or $50 \mu \mathrm{g}$ lipopolysaccharide from Salmonella minnesota R595 (Enzo Life Sciences, Farmingdale, NY) were instilled intratracheally by oropharyngeal aspiration. ${ }^{18}$

\section{BrdU}

Bromodeoxyuridine (BrdU; $0.8 \mathrm{mg}$ in $200 \mu \mathrm{L}$ saline; Sigma-Aldrich, Tokyo, Japan; St. Louis, MO) was injected intraperitoneally at 24 hours before sacrifice. Mouse drinking water was supplemented with $0.8 \mathrm{mg} / \mathrm{mL}$ BrdU for this 24-hour period. For long-term BrdU pulse experiments, mice were injected with $0.8 \mathrm{mg}$ BrdU i.p. after bleomycin treatment and given $0.8 \mathrm{mg} / \mathrm{mL}$ BrdU-containing drinking water until analysis.

\section{Tissue Dissociation}

Mice were anesthetized with pentobarbital. After perfusion with $5 \mathrm{~mL}$ of PBS via the right ventricle, the trachea was cannulated. Pulmonary airspaces were lavaged three times with $1 \mathrm{~mL}$ PBS each time. Either the left or right lobes of the lungs were harvested for flow cytometry. The lobes were cut into small pieces and digested in protease solution [0.2\% collagenase (Wako Pure Chemical Industries, Osaka, Japan), $0.1 \mathrm{mg} / \mathrm{mL}$ Dispase II (Roche, Basel, Switzerland), and 2000 U/mL DNase I (Merck, Darmstadt, Germany) in RPMI medium (Sigma-Aldrich)] for 60 minutes at $37^{\circ} \mathrm{C}$ with trituration by micropipette every 20 minutes. After being passed through a 70- $\mu \mathrm{m}$ strainer (BD Biosciences, San Diego, CA), cells were washed and resuspended in RPMI medium (SigmaAldrich) containing 10\% fetal bovine serum. Peripheral blood cells were treated with red blood cell lysis buffer before analysis by flow cytometry.

\section{Hydroxyproline Assay}

Lung hydroxyproline content was measured as described previously. ${ }^{19,20}$ In brief, mice were sacrificed and the left lungs were harvested. The lungs were minced and suspended in up to $800 \mu \mathrm{L}$ of ultrapure water, after which $800 \mu \mathrm{L}$ of 
$12 \mathrm{~N} \mathrm{HCl}$ was added and the mixture heated for 24 hours at $110^{\circ} \mathrm{C}$. The resulting acid hydrolysates was filtrated through a $0.45-\mu \mathrm{m}$ filter, and $25 \mu \mathrm{L}$ was transferred to new tubes. Next, $25 \mu \mathrm{L}$ of $6 \mathrm{~N} \mathrm{NaOH}, 50 \mu \mathrm{L}$ of citric acetate buffer $(5 \%$ citric acid, $7.24 \%$ sodium acetate, $3.4 \% \mathrm{NaOH}, 1.2 \%$ glacial acetic acid, $\mathrm{pH}$ 6.0), and $400 \mu \mathrm{L}$ of chloramine $\mathrm{T}$ solution (564 mg of chloramine T, $4 \mathrm{~mL}$ of $\mathrm{H}_{2} \mathrm{O}, 4 \mathrm{~mL}$ of $n$-propanol, and $32 \mathrm{~mL}$ of citric-acetate buffer) were added, and the mixture was incubated for 20 minutes at room temperature. Next, $400 \mu \mathrm{L}$ of Ehrlich's solution (4.5 g of 4-dimethylaminobenzaldehyde, $18.6 \mathrm{~mL}$ of $n$-propanol, and $7.8 \mathrm{~mL}$ of $70 \%$ perchloric acid) was added, and the mixture was incubated for a further 15 minutes at $65^{\circ} \mathrm{C}$ before the absorbance (optical density $\mathrm{OD}_{550}$ ) of the solution was measured. The reagents were purchased from Wako Pure Chemical Industries, Sigma-Aldrich Japan, and Tokyo Chemical Industry (Tokyo, Japan).

\section{Flow Cytometry}

Cell suspensions were incubated with anti-CD16/32 antibody to block nonspecific binding, followed by PerCPCy5.5 anti-CD31, phycoerythrin (PE)-Cy7 anti-EpCAM, and allophycocyanin (APC)-Cy7 anti-Ter119 antibodies from Biolegend (San Diego, CA) and APC anti-CD45.2 antibody from BD Biosciences (San Jose, CA). For $\alpha$-SMA and cleaved caspase 3 intracellular staining, cells were fixed with Cytofix/Cytoperm buffer (BD Biosciences) for 20 minutes before incubation with APC anti- $\alpha$-SMA antibody (R\&D Systems, Minneapolis, MN) and anti-cleaved caspase 3 (Cell Signaling Technology, Danvers, MA), followed by incubation with Alexa Fluor 647 anti-rabbit IgG (Life Technologies, Tokyo, Japan; Carlsbad, CA) for cleaved caspase 3. BrdU incorporation was examined using a BrdU flow kit (BD Biosciences). For intracellular OPN staining, single-cell suspensions were cultured in $10 \%$ fetal bovine serum-RPMI medium (Sigma-Aldrich) at $37^{\circ} \mathrm{C}$ with or without the protein transport inhibitor brefeldin A (BFA) for 6 hours, after which adherent cells were collected using trypsin-EDTA. After a washing, the cells were fixed with Cytofix/Cytoperm buffer (BD Biosciences) and then stained with goat anti-OPN primary antibodies (R\&D Systems), followed by Alexa Fluor 647 anti-goat IgG as secondary antibody (Life Technologies). Antibody-labeled cells were washed twice before analysis with a Gallios flow cytometer (Beckman Coulter, Brea, CA). For analysis of cells from SCAT3.1 mice, the FL10 filter was switched to 525BP. Cell sorting was performed on FACSAria (BD Biosciences). Flow cytometry data were analyzed using FlowJo version 7.6.5 software (Tree Star, Ashland, OR).

\section{Immunohistochemistry}

Lungs were fixed with $4 \%$ paraformaldehyde-PBS for 6 hours at $4{ }^{\circ} \mathrm{C}$, treated with $30 \%$ sucrose for cryoprotection, and then embedded in TissueTek optimal cutting temperature compound (Sakura Finetek Japan, Tokyo, Japan). For OPN staining, lungs were filled through the trachea with BFA containing 10\% fetal bovine serum-RPMI medium (SigmaAldrich) and were incubated in the same medium at $37^{\circ} \mathrm{C}$ for 6 hours, before paraformaldehyde fixation. Frozen sections (6 $\mu \mathrm{m}$ thick) were stained with PE anti-EpCAM (BioLegend), APC anti- $\alpha$-SMA (R\&D Systems), anti-collagen type I (Cosmo Bio, Tokyo, Japan), anti-CD45 (BD Biosciences), and anti-OPN (R\&D Systems) primary antibodies, followed by incubation with Alexa Fluor 647 anti-rabbit IgG for collagen type I, Alexa Fluor 546 anti-rat IgG for CD45, and Alexa Fluor 647 anti-goat IgG for OPN (Life Technologies). For BrdU staining, sections were incubated in $500 \mathrm{U} /$ $\mathrm{mL}$ DNase (Calbiochem; EMD Millipore, Billerica, MA) solution for 60 minutes at $37^{\circ} \mathrm{C}$ to retrieve the antigen before staining. Sections were mounted with ProLong Gold antifade reagent (Life Technologies), in some cases containing $2 \mu \mathrm{g} /$ $\mathrm{mL}$ propidium iodide (PI). Sections were photographed using an SP5 confocal microscope (Leica Microsystems, Wetzlar, Germany).

\section{SAGE}

Gene expression analysis was performed using serial analysis of gene expression (SAGE) and next-generation sequencing with an Ion Torrent Personal Genome Machine (PGM) sequencer (Life Technologies). Lung tissue single-cell suspensions from three mice were pooled for each group, and lineage-negative $\left(\mathrm{Lin}^{-}\right) \mathrm{GFP}^{+}$fibroblasts were isolated by cell sorting. RNA was isolated from these cells using a mirVana miRNA isolation kit (Life Technologies). The next-generation sequencing data were generated from $1 \mu \mathrm{g}$ of total RNA. SAGE libraries were constructed using a SOLiD SAGE kit (Life Technologies) according to the manufacturer's protocol. DNA was recovered from the agarose gel using a PureLink gel extraction kit (Life Technologies). DNA fragments of SAGE construct were analyzed on an Agilent 2100 Bioanalyzer platform using a high-sensitivity kit (Agilent Technologies, Santa Clara, CA). Template preparation, emulsion PCR, and Ion Sphere particle enrichment was performed using an Ion Xpress Template kit (Life Technologies) according to the manufacturer's instructions. The quality of the resultant Ion Sphere particle was assessed using a Qubit 2.0 fluorometer (Life Technologies) before the particles were loaded onto a 318 chip (Life Technologies) for sequencing. Raw data from these experiments have been deposited in the NCBI Gene Expression Omnibus (http:// www.ncbi.nlm.nih.gov/geo; accession number GSE42564).

\section{Mapping of Next-Generation Sequencing Data}

For each sample, raw reads from the PGM sequencer were aligned against mouse RefSeq genes (http://hgdownload. cse.ucsc.edu/goldenpath/mm9/database) using BurrowsWheeler alignment software, version 0.6.2, which uses the 25_1 mapping parameter. We generated unique gene counts 
by excluding reads that mapped to contigs of more than one gene; reads mapping to several contigs within an isogroup were counted only once. To include only highly expressed genes and to avoid high dispersion, genes with fewer than 50 tags in both saline-treated and bleomycin-treated groups were eliminated from the library before analysis. Gene ontology (GO) analysis was performed using DAVID (Database for Annotation, Visualization and Integrated Discovery) Bioinformatic Resources software version 6.7 (http://david.abcc. ncifcrf.gov/home.jsp). ${ }^{21}$ Pathway analysis was performed using IPA software version 9.0 (Ingenuity Systems, Redwood City, CA).

\section{qPCR Analysis}

A portion of the mRNA isolated for SAGE was reversetranscribed to cDNA using a Life Technologies highcapacity reverse transcription kit. Quantitative real-time PCR (qPCR) analysis was performed using SYBR Green detection of amplified products and an ABI 7500 real-time PCR system (Life Technologies). Primers used for qPCR were as follows: GAPDH forward 5'-AGTATGACTCCACTCACGGCAA- $3^{\prime}$ and reverse $5^{\prime}$-TCTCGCTCCTGGAAGATGGT-3'; Spp1 forward 5'-GGAGGAAACCAGCCAAGG- $3^{\prime}$ and reverse 5'-TGCCAGAATCAGTCACTTTCAC- $3^{\prime} ; \alpha$-SMA forward $5^{\prime}$-CTGGAGAAGAGCTACGAACTGC- $3^{\prime}$ and reverse $5^{\prime}$-CTGATCCACATCTGCTGGAAGG-3'; S100a4 forward 5'-GGAGCTGCCTAGCTTCCTG-3' and reverse $5^{\prime}$-TCCTGGAAGTCAACTTCATTGTC-3'; Tnc forward 5'-GGGCTATAGAACACCGATGC$3^{\prime}$ and reverse $5^{\prime}$-CATTTAAGTTTCCAATTTCAGGTTC$3^{\prime}$; Fn1 forward $5^{\prime}$-CGGAGAGAGTGCCCCTACTA- $3^{\prime}$ and reverse 5'-CGATATTGGTGAATCGCAGA-3'; Ereg forward $5^{\prime}$-TTGACGCTGCTTTGTCTAGG-3' and reverse $5^{\prime}$-GGATCACGGTTGTGCTGAT-3'; Sfrp1 forward 5'-CAGTTGTGGCTTTTGCATTG- $3^{\prime}$ and reverse $5^{\prime}$-GAGGGAAGGGAGAGGGTTC-3'; Pcolce2 forward 5'-CAAATTCAGGCCGAAAAAGT-3' and reverse 5'-CCACAGTGGGCTTTAGACCT-3'; Gsn forward 5'-CAAAGTCGGGTGTCTGAGG$3^{\prime}$ and reverse 5'-CTTCCCTGCCTTCAGGAAT- $3^{\prime}$; and Efemp 1 forward $5^{\prime}$-CCACAGGGTTACGAAGTGGT-3 ${ }^{\prime}$ and reverse 5'-TCATTGGTGGTCTCACATTCA-3' .

\section{Statistical Analysis}

Statistical comparisons were performed using unpaired $t$-tests (two-tailed). A $P$ value of $<0.05$ was considered statistically significant. Data are expressed as means \pm SEM.

\section{Results}

\section{Characterization of $\mathrm{GFP}^{+}$Cells in the Lungs of Col1a2-GFP Mice}

We first investigated what kinds of cells were labeled with GFP in lungs of Col1a2-GFP reporter mice. ${ }^{16}$ Lungs were dissociated with a protease solution and analyzed by multicolor flow cytometry. $\mathrm{GFP}^{+}$cells comprised a distinct population that was negative for the lineage markers Ter119 (data not shown), CD45, CD31, and EpCAM (Figure 1A). Approximately $70 \%$ to $80 \%$ of $\mathrm{Lin}^{-} \mathrm{GFP}^{+}$cells were PDGFR $\alpha^{+}$; the remainder were PDGFR $\alpha^{-}$(Figure 1B). Immunofluorescence imaging of lung sections revealed $\mathrm{GFP}^{+}$cells to be present in alveolar walls and in peribronchiolar and perivascular regions (Figure 1C). The peribronchiolar and perivascular $\mathrm{GFP}^{+}$cells also expressed $\alpha$-SMA, consistent with these being smooth muscle cells (Figure 1C). ${ }^{15}$ Alveolar $\mathrm{GFP}^{+}$cells were located in the interstitium, surrounded by basement membranes manifested by collagen type IV (Figure 1D). Previous studies have demonstrated that alveolar fibroblasts are PDGFR $\alpha^{+}$, $\mathrm{NG}^{-}, \alpha-\mathrm{SMA}^{-}$, and $\mathrm{CD} 31^{-},{ }^{10,22}$ a phenotype consistent with that observed in alveolar $\mathrm{GFP}^{+}$cells. In summary, $\mathrm{GFP}^{+}$cells in Col1a2-GFP mice comprise a mixed population of alveolar fibroblasts and smooth muscle cells, with alveolar fibroblasts constituting the majority.

\section{Quantitative Analysis of Lung Tissue Cell Dynamics}

A prominent characteristic of pulmonary fibrosis is the accumulation of activated fibroblasts/myofibroblasts in fibrotic lesions. This is caused by the migration of fibroblasts into alveolar spaces and their subsequent proliferation. ${ }^{23}$ Previous studies have demonstrated BrdU uptake of interstitial cells in fibrotic lesions and enhanced in vitro proliferative capacity of fibroblasts from fibrotic organs. ${ }^{24-26}$ However, it remains to be shown in vivo whether this increase in fibroblast numbers mediates the excessive deposition of ECM during fibrosis.

We used a bleomycin-induced lung fibrosis model in Col1a2-GFP mice to investigate changes that occur in lung tissue cell populations. The extent of lung fibrosis occurring in this model was verified by the measurement of hydroxyproline and the expression of profibrotic genes in whole lungs (Supplemental Figure S1). Numbers of leukocytes and of tissue cells such as endothelial cells, epithelial cells, and fibroblasts were determined by multicolor flow cytometry (Figure 2A). The number of CD45 ${ }^{+}$leukocytes in the lungs was elevated at days 7 and 14 after bleomycin administration (Figure 2B), which may reflect the infiltration of inflammatory cells. $\mathrm{CD} 31^{+}$endothelial cell numbers did not change significantly after bleomycin administration (Figure 2B). In contrast, $\mathrm{EpCAM}^{+}$epithelial cells, a population that includes alveolar type II cells, bronchiolar epithelial cells, and possibly alveolar type I cells, ${ }^{27}$ markedly decreased after bleomycin treatment (Figure 2B). This probably resulted from the denudation of the epithelium that is induced by bleomycin toxicity. Contrary to expectations, the numbers of $\mathrm{Lin}^{-} \mathrm{GFP}^{+}$fibroblasts in whole-lung tissue preparations remained constant throughout bleomycininduced lung fibrosis (Figure 2B). Even at days 14 and 21 after bleomycin administration, which fall within the peak 

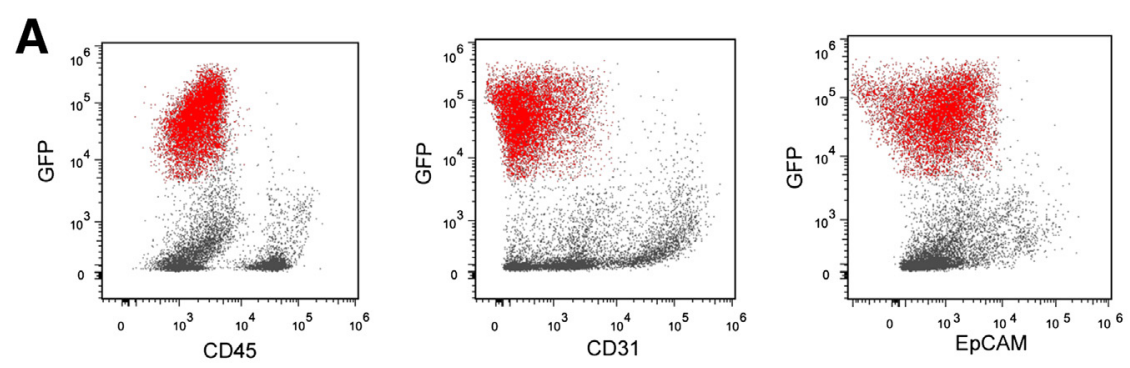

Lin- GFP ${ }^{+}$cells

Whole lung cells

B Gate: Lin.GFP.

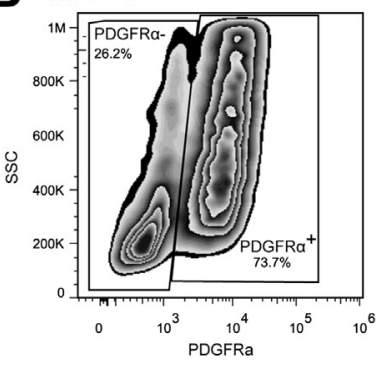

C

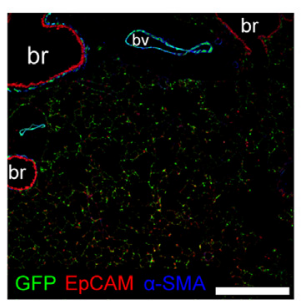

D

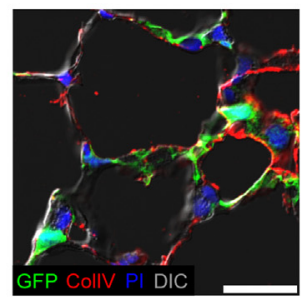

Figure 1 Characterization of $\mathrm{GFP}^{+}$cells in the lungs of Col1a2-GFP mice. A: Lung single-cell suspensions were stained with antibodies against CD45, CD31, and EpCAM. Lin (ie, Ter119- CD45 $\mathrm{CD}^{-} 1^{-} \mathrm{EpCAM}^{-}$) $\mathrm{GFP}^{+}$cells (red) made up a distinctive $\mathrm{CD}^{-} 5^{-} \mathrm{CD}^{-} 1^{-} \mathrm{EpCAM}^{-}$population. $\mathbf{B}$ : $\mathrm{Lin}^{-} \mathrm{GFP}^{+}$cells comprised $70 \%$ to $80 \% \mathrm{PDGFR}^{+}$ cells and $20 \%$ to $30 \%$ PDGFR $\alpha^{-}$cells. C: Lung sections from Col1a2-GFP mice stained for EpCAM (red) and $\alpha$-SMA (blue). D: Lung sections from Col1a2-GFP mice stained for collagen type IV (red) and PI (blue). Differential interference contrast (DIC) is also shown (gray). Scale bars: $400 \mu \mathrm{m}$ (C); $25 \mu \mathrm{m}$ (D). br, bronchiole; bv, blood vessel. period for fibrosis ${ }^{28}$ there was no difference in $\mathrm{Lin}^{-} \mathrm{GFP}^{+}$ fibroblast numbers, compared with saline-treated control (Figure 2C), nor was any increase in fibroblast number observed at day 28 (data not shown).

To technically validate these results, we used the lipopolysaccharide-induced acute lung injury model as a negative control in which an increase in fibroblasts is not expected. We observed a massive increase in leukocyte infiltration into the lungs and alveolar air spaces after lipopolysaccharide administration, but the numbers of lung tissue cells including fibroblasts remained unchanged (Supplemental Figure S2). In the absence of a suitable positive control model in which an increase in lung fibroblasts would be expected, we used a tumor lung metastasis model to confirm that increases in lung tissue cells could be detected. At 18 days after intravenous injection of $4 \times 10^{6}$ Lewis lung carcinoma cells (3LL cells), we observed a dramatic increase in $\mathrm{EpCAM}^{+}$ tumor cells without any increase in the other tissue cell populations (Supplemental Figure S3). These results indicate that flow-cytometric analysis after complete digestion of lung tissue is an appropriate way to quantify tissue cell numbers. Thus, the excessive accumulation of ECM that occurs during lung fibrosis cannot be accounted for by an increase in fibroblast numbers.

\section{Qualitative Changes in Fibroblasts after Bleomycin Treatment}

Previous studies have shown that exposure of fibroblasts to bleomycin induces an activated phenotype that includes increased $\alpha$-SMA and collagen type I expression. ${ }^{4}$ However, these studies identified fibroblasts only by their stromal localization or by their adhering plastic dishes. Because there was no quantitative increase in fibroblast numbers during fibrosis, we next examined whether there are any phenotypic changes in collagen type I-producing fibroblasts after bleomycin treatment. At day 14, we observed a greater proportion of $\mathrm{GFP}^{\text {hi }}$ fibroblasts in bleomycin-treated mice, which indicates increased expression of Colla2 (Figure 3A). GFP $^{\text {hi }}$ fibroblasts had high side scatter (SSC) (Figure 3A). Furthermore, many SSC ${ }^{\text {hi }}$ fibroblasts had increased forward scatter (FSC) (Figure 3B). Of the bleomycin-treated fibroblasts in the GFP $^{\text {hi }}$ SSC $^{\text {hi }}$ gate (Figure $3 \mathrm{~A}$ ), $77.3 \pm 2.5 \%$ also fell into the $\mathrm{FSC}^{\text {hi }} \mathrm{SSC}^{\text {hi }}$ gate (Figure 3B), compared with $44.2 \pm 2.3 \%$ of saline-treated fibroblasts (data not shown) $(P<0.01)$. These data suggest that cell size and intracellular organelle complexity increase in activated fibroblasts. These changes were also quantifiable as greater mean fluorescent intensity values for GFP, SSC, and FSC in $\mathrm{Lin}^{-} \mathrm{GFP}^{+}$cells from bleomycin-treated mice (Figure 3C).

To investigate whether $\mathrm{Lin}^{-} \mathrm{GFP}^{+}$fibroblasts differentiate into myofibroblasts, we also measured $\alpha$-SMA expression by flow cytometry (Figure 3D). In normal lungs (day 0), $4.41 \pm$ $0.49 \%$ of $\mathrm{Lin}^{-} \mathrm{GFP}^{+}$cells were $\alpha-\mathrm{SMA}^{+}$(Figure 3D), probably representing peribronchiolar and perivascular smooth muscle cells (Figure 3E). At days 7 and 14 after bleomycin administration, the proportion of $\alpha-\mathrm{SMA}^{+}$cells was almost twice as high as at day 0 (Figure 3D). By day 21, however, the proportion of $\alpha-\mathrm{SMA}^{+}$cells had returned to normal levels, which is consistent with previous studies. ${ }^{10,29}$

\section{Histological Analysis of Col1a2-GFP Mouse Lungs}

Flow-cytometric analysis of fibroblasts revealed clear phenotypic changes associated with activation by bleomycin. We next investigated whether these changes could be observed histologically. In saline-treated lungs, $\alpha$-SMA expression was confined to peribronchiolar and perivascular 
A
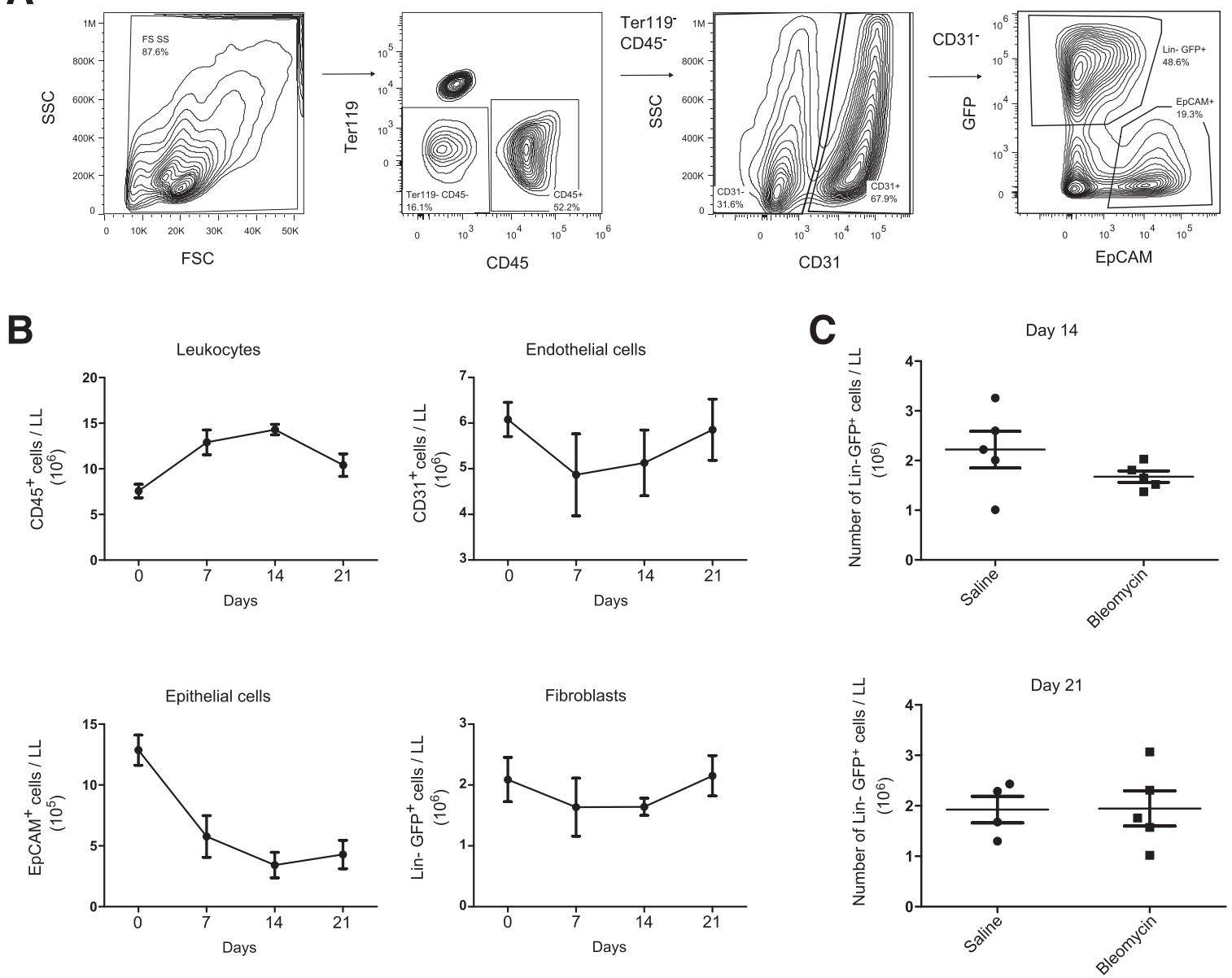

Figure 2 Changes in lung tissue cell populations during bleomycin-induced pulmonary fibrosis. A: Enzymatically dissociated lung cells from bleomycin-treated Col1a2-GFP mice were stained for lineage markers and analyzed by flow cytometry. B: CD45 ${ }^{+}$leukocytes, CD31 ${ }^{+}$endothelial cells, EpCAM ${ }^{+}$epithelial cells, and Lin ${ }^{-}$ $\mathrm{GFP}^{+}$fibroblasts were quantified by flow cytometry at 7, 14, and 21 days after bleomycin administration. Day 0 data were from untreated mice. C: Numbers of Lin ${ }^{-}$GFP $^{+}$ cells in the lungs did not differ between saline- or bleomycin-treated mice at 14 and at 21 days after bleomycin administration, as quantified by flow cytometry. Data are expressed as means \pm SEM (B) or as both means \pm SEM and individual data points (C). $n=3$ or 4 (B); 4 or 5 (C). LL, left lobe.

smooth muscle cells, with most alveolar fibroblasts negative for $\alpha$-SMA (Figure 3E). At day 14 after bleomycin treatment, there were a large number of $\mathrm{GFP}^{+}$fibroblast clusters (Figure 3E), in which the fibroblasts were surrounded by extracellular collagen type I (Figure 3F). Thus, bleomycin treatment induced the formation of fibrotic regions made up of fibroblast clusters. Many of the $\mathrm{GFP}^{+}$fibroblasts in these clusters were $\alpha-\mathrm{SMA}^{+}$(Figure 3E), suggesting that these cells were actually myofibroblasts. In bleomycin-treated lungs, $\alpha$-SMA expression extended beyond the peribronchiolar and perivascular regions into the alveolar region, in accord with the greater numbers of $\mathrm{GFP}^{+} \alpha-$ $\mathrm{SMA}^{+}$cells detected by flow cytometry. The fibroblasts making up the fibrotic regions observed at day 14 after bleomycin treatment had relatively large cell sizes, compared with those in saline-treated lungs (Figure 3E). Taken together with the increase of $\mathrm{GFP}^{+} \alpha-\mathrm{SMA}^{+}$cells detected by flow cytometry (Figure 3D), these results suggest a tendency for $\mathrm{GFP}^{+}$alveolar fibroblasts to differentiate into myofibroblasts after bleomycin treatment. These results also suggest that $\mathrm{GFP}^{+}$fibroblasts play a central role in the formation of fibrotic regions.

\section{Proliferation and Apoptosis of Fibroblasts after Bleomycin Treatment}

Despite lack of change in absolute numbers of lung fibroblasts after treatment with bleomycin, as measured by flow cytometry, $\mathrm{GFP}^{+}$fibroblasts in bleomycin-treated lungs displayed clustering and increased cell density in fibrotic regions, which is suggestive of a proliferative response. These conflicting results led us to hypothesize that both proliferation and cell death were accelerated during fibrosis in the lungs, in balance with each other. To examine fibroblast apoptosis, we investigated the activation of caspase 3 using an anti-cleaved caspase 3 antibody (Figure 4A). We treated Col1a2-GFP mice with bleomycin, then measured apoptosis of lung tissue cells by flow cytometry (Figure 4B). Only a very small proportion $(0.1 \%$ to $0.8 \%)$ of endothelial cells were apoptotic during bleomycin-induced fibrosis 

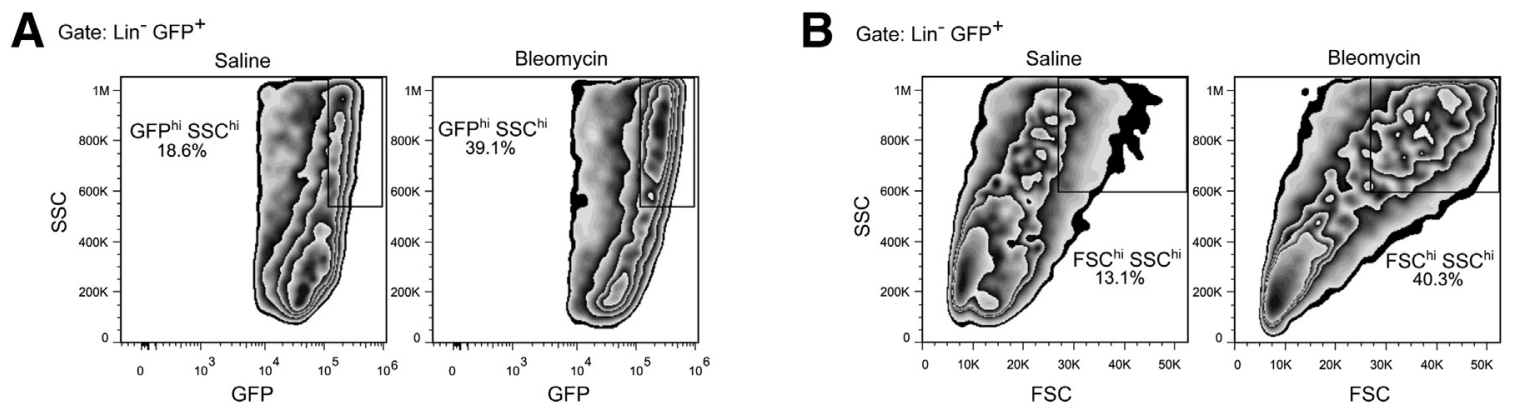

C
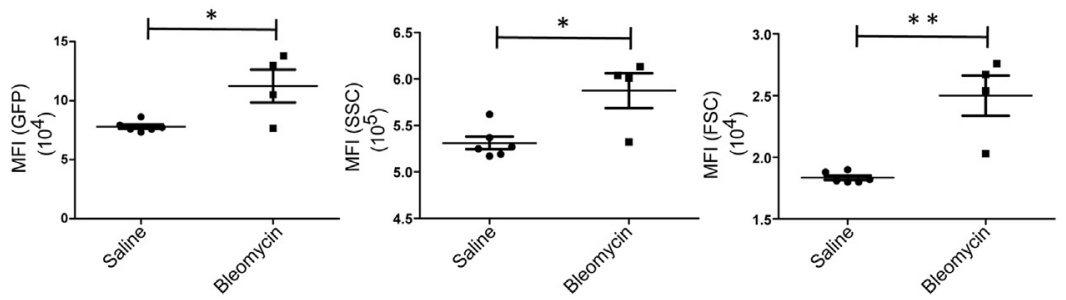

D

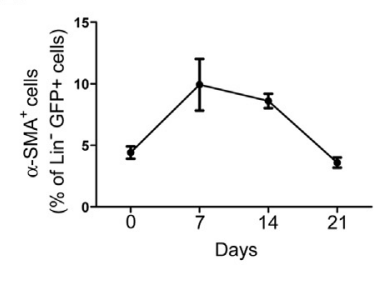

E
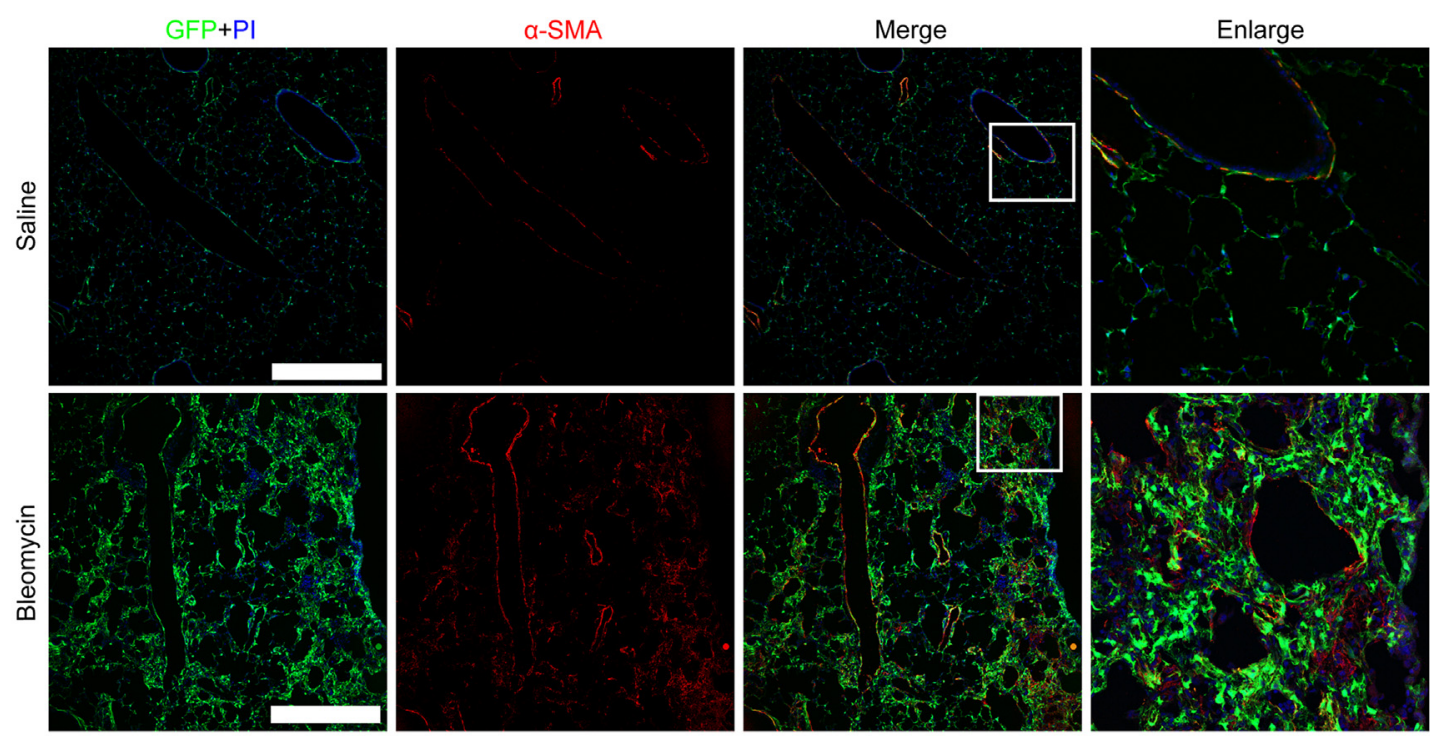

F

GFP+PI

Collagen |

Merge
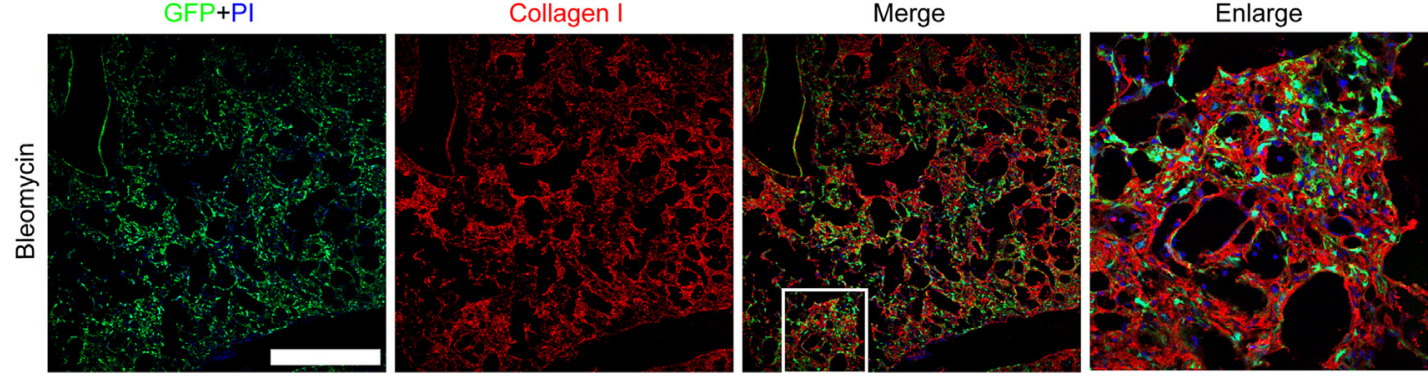

Figure 3 Qualitative changes in fibroblasts during bleomycin-induced lung fibrosis. A and B: Lung cells from Col1a2-GFP mice at 14 days after saline or bleomycin administration were stained for lineage markers. Lin ${ }^{-}$GFP $^{+}$fibroblasts were plotted as SSC versus GFP (A) and SSC versus FSC (B). C: The mean fluorescent intensities (MFI) of GFP, SSC, and FSC signals of $\mathrm{Lin}^{-} \mathrm{GFP}^{+}$fibroblasts from Col1a2-GFP mice at 14 days after saline or bleomycin administration. D: Lung cells from Col1a2-GFP mice at 0, 7, 14, and 21 days after bleomycin administration were stained for lineage markers and $\alpha$-SMA and the proportion of $\alpha-S M A^{+}$cells was evaluated by flow cytometry. $\mathbf{E}$ and $\mathbf{F}$ : Lungs from Col1a2-GFP mice at 14 days after saline $(\mathbf{E})$ or bleomycin $(\mathbf{E}$ and $\mathbf{F})$ administration were stained with antibodies against PI and $\alpha$-SMA (E) or PI and collagen type I (F). Boxed regions in the Merge column correspond to images in the Enlarge column. Original magnification, $\times 400$. Data are expressed as means \pm SEM (D) or as both means \pm SEM and individual data points (C). $n=4$ or 6 (C); $n=3$ or 4 (D). ${ }^{*} P<0.05,{ }^{* *} P<0.01$. Scale bar $=500 \mu \mathrm{m}$. 
(Figure 4B). In contrast, the proportion of epithelial cells that were apoptotic dramatically increased after bleomycin treatment, from $1.3 \pm 0.2 \%$ in untreated mice to $6.0 \pm 0.3 \%$ on day 14 after bleomycin treatment (Figure 4B). This result highlights the severe injury sustained by the lung epithelium during bleomycin-induced fibrosis. Unlike endothelial and epithelial cells, in $\mathrm{GFP}^{+}$fibroblasts the apoptosis peaked at day 7 , although the proportion of apoptotic cells observed on day 14 remained elevated above those seen at day 0 (Figure 4B).

We also examined the apoptosis of tissue cells using ROSA-CAG-SCAT3.1 knockin mice (SCAT3.1 mice), in which apoptotic cells are detected with fluorescent fusion protein. ${ }^{17,30,31}$ In these mice, apoptotic cells form a population with a reduced fluorescence resonance energy transfer (FRET) signal and a slightly elevated ECFP signal, compared with nonapoptotic cells (Supplemental Figure S4). The kinetics of apoptosis obtained with SCAT3.1 mice were similar to those obtained with anti-cleaved caspase 3 antibody (Supplemental Figure S5). These results demonstrate the different sensitivities of tissue cells to apoptosis during the lung remodeling caused by bleomycin.

We next used BrdU to investigate the proliferation of lung tissue cells during bleomycin-induced fibrosis. At 24 hours after bleomycin-treated Col1a2-GFP mice were injected intraperitoneally with BrdU, their lungs were harvested and the number of $\mathrm{BrdU}^{+}$cells present was counted by flow cytometry (Figure 4C). Uptake of BrdU by endothelial cells peaked at day 7 and then gradually decreased (Figure 4D). Uptake by epithelial cells similarly peaked at day 7, but was sustained at similar levels at days 14 and 21 (Figure 4D). $\mathrm{GFP}^{+}$fibroblasts also had the greatest BrdU incorporation at 7 days after bleomycin administration, followed by a steady decrease across days 14 and 21 (Figure 4D), a pattern similar

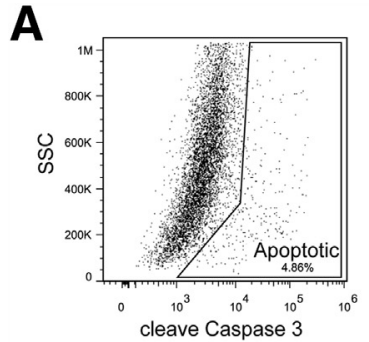

C

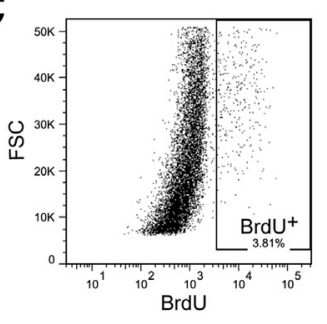

D

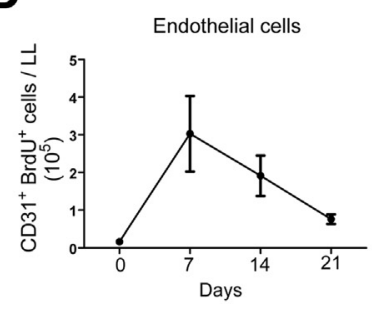

E

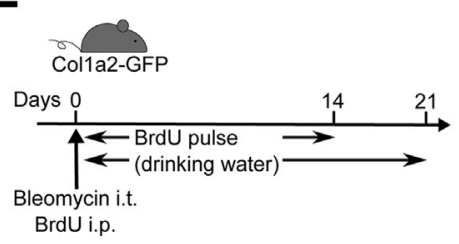

B

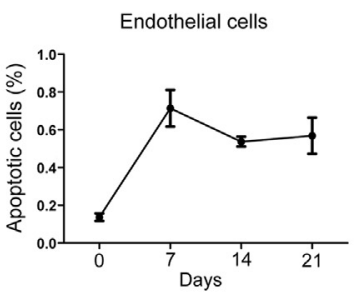

$\mathbf{F}$
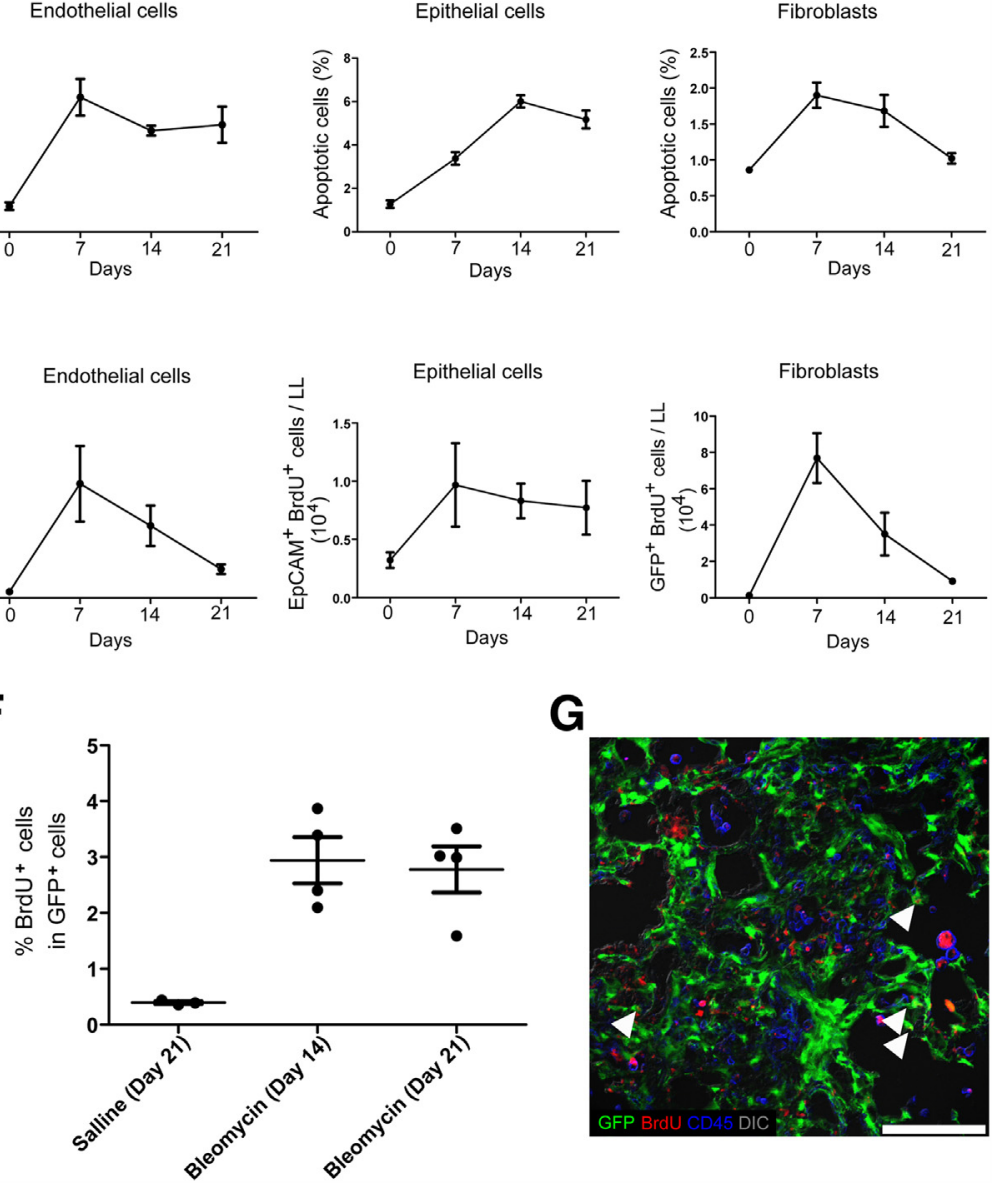

G

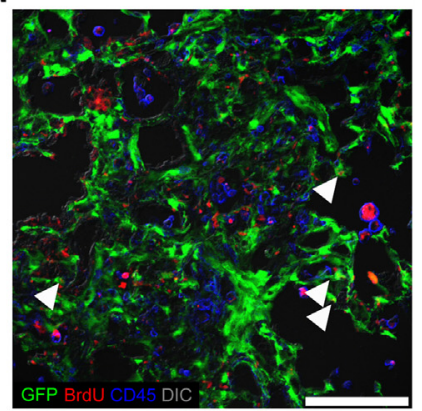

Figure 4 Proliferation and apoptosis of fibroblasts in bleomycin-induced pulmonary fibrosis. A: Identification of apoptotic cells by flow cytometry with anti-cleaved caspase 3 antibody. B: The proportion of apoptotic cells in different lung cell populations from Col1a2-GFP mice at 0, 7, 14, and 21 days after bleomycin administration was analyzed by flow cytometry after staining for CD31 (endothelial cells), EpCAM (epithelial cells), and CD45 (leukocytes). C: Identification of $\mathrm{BrdU}^{+}$cells by flow cytometry. D: Col1a2-GFP mice were pulsed with BrdU for 24 hours before analysis at 0, 7, 14, or 21 days after bleomycin administration. Lung cells were stained for BrdU and CD31, EpCAM, and CD45 and BrdU ${ }^{+}$cell numbers were quantitated. E: Experimental design for long-term BrdU pulse experiments. F: After long-term BrdU pulse, lung cells were stained for BrdU and analyzed for the proportion of BrdU ${ }^{+}$cells among GFP ${ }^{+}$cells. G: Representative lung section from Col1a2-GFP mice at 14 days after bleomycin administration and long-term BrdU pulse, with staining for GFP (green), BrdU (red), and CD45 (blue). BrdU ${ }^{+} \mathrm{GFP}^{+}$cells are indicated by arrowheads. DIC is also shown (gray). Data are expressed as means \pm SEM (B and F) or as both means \pm SEM and individual data points (D). $n=3$ or 4 . Scale bar $=100 \mu \mathrm{m}$. 
to that observed for apoptotic $\mathrm{Lin}^{-}$cells (Figure 4B). Similar experiments using fluorescent ubiquitination-based cell cycle indicator (Fucci) mice (FucciG1-\#639 and FucciS/G2/M\#474 double-transgenic mice), which enable quantification of proliferating cells independent of pulse time, ${ }^{32}$ yielded results consistent with those obtained from BrdU-uptake experiments (Supplemental Figure S6).

To examine whether $\mathrm{GFP}^{+}$fibroblast clusters are dependent on cell proliferation, we treated Col1a2-GFP mice with a longterm BrdU pulse after bleomycin treatment (Figure 4E). In this experiment, approximately $30 \%$ of $\mathrm{CD}^{4} 5^{+}$leukocytes in the lungs were $\mathrm{BrdU}^{+}$at day 14 or 21 after bleomycin treatment (Supplemental Figure S7). More than 10\% of endothelial and epithelial cells were $\mathrm{BrdU}^{+}$at day 21 after bleomycin treatment (Supplemental Figure S7). In contrast, only 3\% of GFP ${ }^{+}$ cells in bleomycin-treated mice (day 14 and 21) were $\mathrm{BrdU}^{+}$ (Figure 4F). Immunofluorescence staining of lung sections from bleomycin-treated mice (day 14) revealed BrdU staining among $\mathrm{CD}_{4} 5^{+}$leukocytes and other stromal cells, which might have included endothelial and epithelial cells (Figure 4G and Supplemental Figure S7). However, only a small portion of $\mathrm{GFP}^{+}$cells were $\mathrm{BrdU}^{+}$(Figure 4G), and most of the $\mathrm{GFP}^{+}$ cells in fibrotic clusters were $\mathrm{BrdU}^{-}$, suggesting that the clusters do not form through proliferation alone.

In summary, bleomycin treatment induced both apoptosis and proliferation of lung tissue cells. Although proliferative $\mathrm{GFP}^{+}$fibroblasts were detected, particularly in the early phase of fibrosis, the concurrent induction of apoptosis kept the overall number of $\mathrm{GFP}^{+}$fibroblasts constant, and for the most part the $\mathrm{GFP}^{+}$fibroblast clusters were not formed only by proliferation.

\section{The Contribution of Bone Marrow-Derived Cells to the Lung $\mathrm{GFP}^{+}$Fibroblast Population}

Several studies have reported that $\mathrm{CD} 45^{+}$collagen type Ipositive circulating mesenchymal cells (so-called fibrocytes) contribute to fibrogenesis after bleomycin-induced lung injury. ${ }^{33,34}$ However, we detected almost no $\mathrm{GFP}^{+}$cells in the peripheral blood cells, most of which were $\mathrm{CD} 45^{+}$, of saline- or bleomycin-treated Col1a2-GFP mice at day 14 after treatment (Figure 5A). To investigate the extent to which lung $\mathrm{GFP}^{+}$fibroblasts were supplied from the bone marrow via the circulation, we generated parabiotic pairs composed of Col1a2-GFP (CD45.2 $2^{+}$) and congenic wild-type (WT; $\mathrm{CD} 45.1^{+}$) mice (Figure 5B). At 6 weeks after surgery, we treated mice with bleomycin or saline. Lungs were then harvested at day 21 after bleomycin treatment for analysis by flow cytometry. Chimerism of $40 \%$ to $60 \%$ (B-cell congenic markers) was observed, demonstrating that circulating blood was shared in the parabiotic mice (Figure 5C). However, in WT lungs only a very small proportion $(<0.5 \%)$ of $\mathrm{Lin}^{-}$cells were $\mathrm{GFP}^{+}$after treatment with either saline or bleomycin (Figure 5D). Similarly, fluorescent microscopy analysis of lung sections at 21 days after bleomycin treatment did not detect any $\mathrm{GFP}^{+}$fibroblasts in WT lungs, in stark contrast to the $\mathrm{GFP}^{+}$fibroblasts that were prominent in fibrotic regions of Col1a2-GFP lungs (Figure 5E). These results suggest that the $\mathrm{GFP}^{+}$fibroblasts in fibrotic regions in the lungs are not supplied from the bone marrow or the circulation during fibrosis. Instead, resident cells in the lungs, probably resident fibroblasts, are the likely progenitors of the activated fibroblasts that form fibrotic regions.

\section{Gene Expression Analysis of $\mathrm{GFP}^{+}$Fibroblasts}

To further investigate phenotypic changes in $\mathrm{GFP}^{+}$fibroblasts, we generated a whole-genome gene expression profile for these cells. We used next-generation sequencing to perform SAGE analysis on $\mathrm{GFP}^{+}$lung fibroblasts sorted by fluorescence-activated cell sorting at 14 days after saline or bleomycin treatment. The purity of $\mathrm{GFP}^{+}$cells after sorting was $94.5 \%$ and $98.0 \%$ for saline and bleomycin treatment, respectively. We identified 2,973,937 SAGE tags $(1,080,798$ tags from saline-treated $\mathrm{GFP}^{+}$fibroblasts and 1,893,139 tags from bleomycin-treated $\mathrm{GFP}^{+}$fibroblasts), representing 13,894 distinct transcripts. The number of tag sequences from bleomycin-treated $\mathrm{GFP}^{+}$fibroblasts was normalized to that of saline-treated $\mathrm{GFP}^{+}$fibroblasts before gene expression was compared between the two libraries. There were 213 genes with a greater than threefold difference between the saline and bleomycin groups. The 40 transcripts that increased the most after bleomycin treatment, compared with control, are listed in Table 1 . The 40 genes that were most down-regulated are listed in Supplemental Table S1. The most highly up-regulated transcript (213-fold) was secreted phosphoprotein 1 (Sppl). To confirm the SAGE results, qPCR was performed for representative transcripts. There was good correlation between the results of the SAGE and qPCR analyses (Supplemental Figure S8).

Some of the 40 most up-regulated genes that were induced by bleomycin treatment have already been identified as important in fibrosis. Sppl is known to be up-regulated in idiopathic pulmonary fibrosis patients, as well as in the bleomycin-induced lung fibrosis model in mice. ${ }^{35,36}$ Cytokine receptor-like factor 1 ( $\mathrm{Crlfl}$ ) expressed by epithelial cells was recently reported to have antifibrotic actions. ${ }^{37}$ The present data, however, suggest that fibroblasts also express Crlf1. The expression of S100a4, a fibroblast marker, was low in saline-treated mice but dramatically up-regulated in bleomycin-treated mice. Gelsolin (Gsn), which is involved in the rearrangement of cytoskeletal structure and is necessary for the development of pulmonary fibrosis, ${ }^{38}$ showed a remarkable decrease of tag number, from 19,346 to 2548 (Supplemental Table S1). Interestingly, expression of the latent transforming growth factor $\beta$ binding protein 4 gene (Ltbp4) decreased markedly at day 14 after bleomycin treatment (Supplemental Table S1). Ltbp4 regulates TGF- $\beta 1$ bioavailability in pulmonary fibrosis. ${ }^{39}$ Despite these insights into how changes in fibroblast gene expression can influence fibrogenesis, the significance of changes in the expression of many other genes remains elusive. 
A

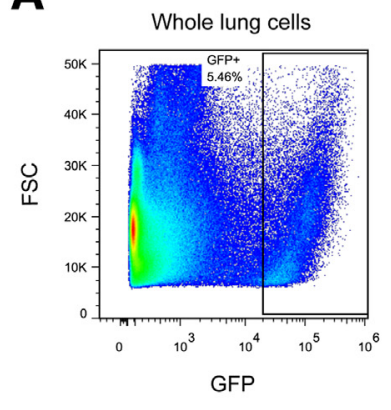

C

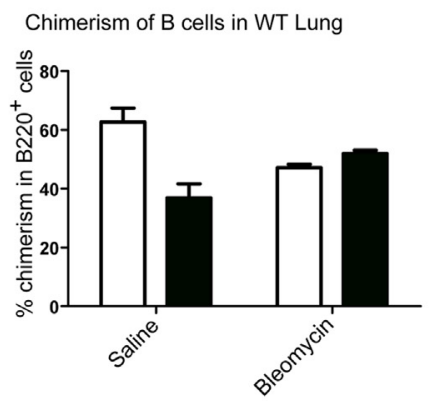

$\mathbf{E}$
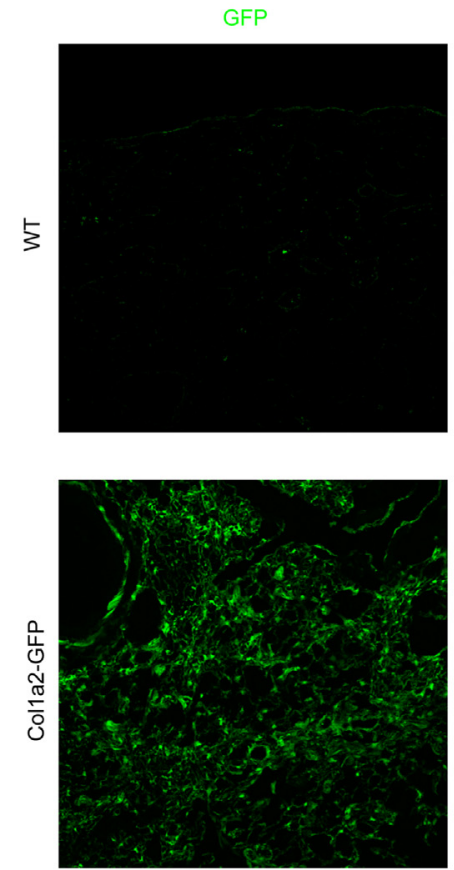

Chimerism of B cells in Col1a2-GFP Lung
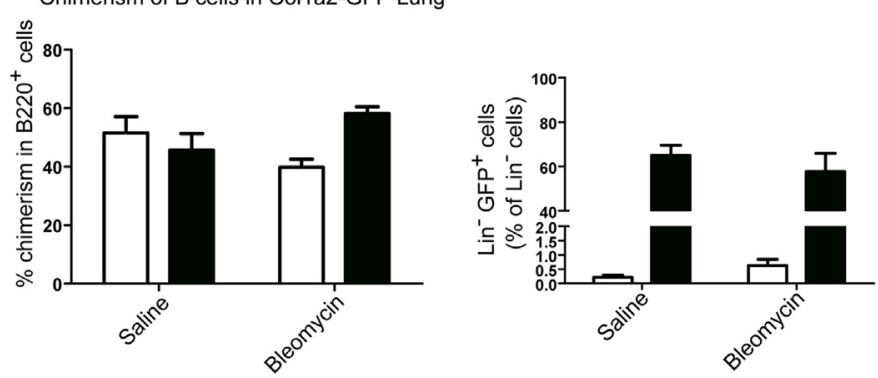

PI
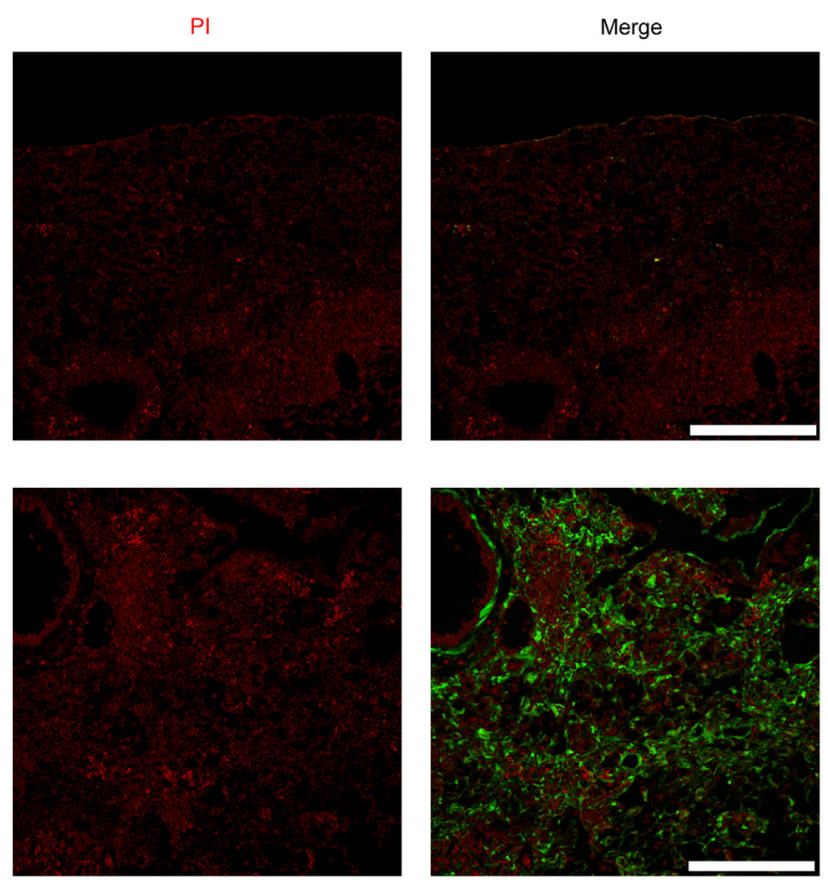

Figure 5 The contribution of bone marrow-derived cells to the lung $\mathrm{GFP}^{+}$fibroblast population. A: Whole-lung cells (saline treatment) and peripheral blood cells (saline or bleomycin treatment) were analyzed by flow cytometry at 14 days after treatment. Red plots are dense area, and blue plots are sparse area. B: Parabiotic pairs of WT $\left(C D 45.1^{+}\right)$mice and Col1a2-GFP mice $\left(C D 45.2^{+}\right)$were intratracheally instilled with bleomycin or saline. Each parabiotic pair received the same treatment. C: Chimerism of B cells (B220 cells) in the lungs of WT (white bars) or Col1a2-GFP (black bars) mice was determined from CD45.1 and CD45.2 expression. D: The proportion of GFP ${ }^{+}$cells in WT (white bars) and Col1a2-GFP (black bars) lungs was measured by flow cytometry. E: Representative lung sections of parabiotic WT and Col1a2-GFP mice stained for GFP and PI and imaged by confocal fluorescence microscopy. Data are expressed as means \pm SEM (C and D). Scale bar $=250 \mu \mathrm{m}$. PBL, peripheral blood.

Previous studies have demonstrated roles for TGF- $\beta$, EGF, and IL-1 $\beta$ in pulmonary fibrosis. ${ }^{5,40,41}$ By analyzing the gene expression profiles of fibroblasts with IPA software, we confirmed that these molecules worked directly as upstream gene regulators in fibroblasts (Supplemental Table S2). We also categorized up-regulated genes by molecular function, such as cytokine, chemotaxis, cell adhesion, and DNA binding (Supplemental Tables S3, S4, S5, and S6) 
Table 1 The 40 Most up-Regulated Genes in $\mathrm{GFP}^{+}$Fibroblasts at 14 Days after Bleomycin Treatment

\begin{tabular}{|c|c|c|c|}
\hline \multirow[b]{2}{*}{ Symbol } & \multicolumn{2}{|c|}{ Tags, no. } & \multirow[b]{2}{*}{ Fold change } \\
\hline & Saline & Bleomycin & \\
\hline Spp1 & 57 & 12,155 & 213.2 \\
\hline Crlf1 & 1 & 212 & 212.0 \\
\hline Chl1 & 1 & 157 & 157.0 \\
\hline Cthrc1 & 1 & 97 & 97.0 \\
\hline Ereg & 7 & 449 & 64.1 \\
\hline Anxa8 & 2 & 108 & 54.0 \\
\hline $\operatorname{Lrg} 1$ & 2 & 104 & 52.0 \\
\hline$H p$ & 28 & 1,077 & 38.5 \\
\hline 9930013L23Rik & 4 & 103 & 25.8 \\
\hline Gjb3 & 4 & 98 & 24.5 \\
\hline C1qtnf6 & 13 & 298 & 22.9 \\
\hline$S d c 1$ & 6 & 136 & 22.7 \\
\hline Areg & 3 & 66 & 22.0 \\
\hline Tnc & 40 & 824 & 20.6 \\
\hline S100a4 & 116 & 2,060 & 17.8 \\
\hline Fst & 36 & 568 & 15.8 \\
\hline Ildr2 & 6 & 86 & 14.3 \\
\hline Mcm6 & 6 & 74 & 12.3 \\
\hline Hspb7 & 9 & 106 & 11.8 \\
\hline Timp1 & 163 & 1,883 & 11.6 \\
\hline Slc7a2 & 8 & 88 & 11.0 \\
\hline Sfrp1 & 165 & 1,702 & 10.3 \\
\hline Fkbp5 & 10 & 95 & 9.5 \\
\hline Serpina3m & 18 & 164 & 9.1 \\
\hline Rnf149 & 21 & 191 & 9.1 \\
\hline Fn1 & 1018 & 8,890 & 8.7 \\
\hline Chst11 & 10 & 87 & 8.7 \\
\hline Il11 & 8 & 66 & 8.3 \\
\hline Nrep * & 48 & 395 & 8.2 \\
\hline Cd109 & 16 & 118 & 7.4 \\
\hline 1110038B12Rik & 15 & 107 & 7.1 \\
\hline Slpi & 23 & 164 & 7.1 \\
\hline Rgs16 & 25 & 176 & 7.0 \\
\hline Сур26b1 & 11 & 75 & 6.8 \\
\hline Saa3 & 219 & 1,474 & 6.7 \\
\hline Nek6 & 12 & 78 & 6.5 \\
\hline Inhba & 14 & 90 & 6.4 \\
\hline Col12a1 & 30 & 189 & 6.3 \\
\hline Col7a1 & 19 & 118 & 6.2 \\
\hline Wisp1 & 30 & 180 & 6.0 \\
\hline
\end{tabular}

*Alias DOH4S114.

To assess the functional significance of changes in the gene expression profile of $\mathrm{GFP}^{+}$fibroblasts after bleomycin treatment, we used DAVID software to analyze which GO terms were enriched among genes that were up-regulated greater than threefold (Table 2). ${ }^{21}$ Many of the up-regulated genes related to the ECM, suggesting that after bleomycin treatment the activated $\mathrm{GFP}^{+}$fibroblasts were involved in construction of ECM networks at fibrotic lesions. Genes related to the binding of extracellular components, such as glycosaminoglycan, were also up-regulated. We also used IPA software to quantify the specific changes in biological function associated with changes in gene expression in activated $\mathrm{GFP}^{+}$fibroblasts (Table 3 ). The IPA analysis yields an activation $z$-score that indicates the extent to which biological function is increased (positive values) or decreased (negative values). Genes that promote cell proliferation were up-regulated in activated $\mathrm{GFP}^{+}$fibroblasts, whereas functions linked to cell death, such as apoptosis and necrosis, had negative activation $z$-scores. These results indicate that activated $\mathrm{GFP}^{+}$fibroblasts are more resistant to cell death. Functions related to cell migration (including cell movement, invasion, and chemotaxis) were increased. Overall, these results mirror the assumed roles of fibroblasts in fibrogenesis; activated fibroblasts migrate to damaged sites and generate fibrotic legions by secreting ECM components. These data also support a central role for $\mathrm{GFP}^{+}$fibroblasts in bleomycininduced fibrogenesis.

\section{Identification of OPN as an Early Activation Marker of Lung Fibroblasts in Bleomycin-Induced Fibrosis}

Because the OPN gene Sppl had both the highest fold change and the high read tag number in bleomycin-treated $\mathrm{GFP}^{+}$fibroblasts, we examined the possibility that OPN might serve as an activation marker for lung fibroblasts. Although $\mathrm{T}$ cells and macrophages are well-known sources of OPN, tissue cells may be important alternative sources of this protein. ${ }^{42}$ We used qPCR to confirm Sppl expression levels in mRNA collected from sorted $\mathrm{GFP}^{+}$fibroblasts. Sppl mRNA levels were approximately 500 times higher in bleomycin-treated fibroblasts than in saline-treated fibroblasts (Figure 6A). To confirm protein expression, we cultured lung fibroblasts with BFA and stained them with an antibody against OPN before analysis by flow cytometry (Figure 6B). Of the $\mathrm{Lin}^{-}$bleomycin-treated $\mathrm{GFP}^{+}$fibroblasts, $9.0 \pm 1.1 \%$ were $\mathrm{OPN}^{+}$, compared with only $0.37 \pm$ $0.07 \%$ of saline-treated $\mathrm{GFP}^{+}$fibroblasts (Figure 6C).

Table 2 Gene Ontology (G0) Terms That Were Enriched Amongst Genes That Were up-Regulated Greater than Threefold in $\mathrm{GFP}^{+}$ Fibroblasts at 14 Days after Bleomycin Treatment

\begin{tabular}{lcl}
\hline G0 term & Genes, no. & $P$ value \\
\hline Extracellular region & 40 & $2.58 \times 10^{-14}$ \\
Extracellular region part & 25 & $4.17 \times 10^{-11}$ \\
Extracellular matrix part & 11 & $3.04 \times 10^{-10}$ \\
Proteinaceous extracellular matrix & 16 & $5.03 \times 10^{-10}$ \\
Extracellular matrix & 16 & $8.70 \times 10^{-10}$ \\
Collagen & 5 & $5.60 \times 10^{-06}$ \\
Cell adhesion & 14 & $4.81 \times 10^{-05}$ \\
Biological adhesion & 14 & $4.90 \times 10^{-05}$ \\
Glycosaminoglycan binding & 7 & $7.71 \times 10^{-05}$ \\
Basement membrane & 6 & $1.01 \times 10^{-04}$ \\
Pattern binding & 7 & $1.46 \times 10^{-04}$ \\
Polysaccharide binding & 7 & $1.46 \times 10^{-04}$ \\
Heparin binding & 6 & $1.67 \times 10^{-04}$ \\
Growth factor activity & 7 & $2.48 \times 10^{-04}$ \\
Extracellular structure organization & 7 & $3.59 \times 10^{-04}$ \\
Extracellular matrix organization & 6 & $4.44 \times 10^{-04}$ \\
\hline
\end{tabular}


Table 3 Changes in Biological Function Associated with Changes in Gene Expression in GFP ${ }^{+}$Fibroblasts at 14 Days after Bleomycin Treatment

\begin{tabular}{lllr}
\hline Function annotation & $P$ value & Predicted activation state & Activation Z-score \\
\hline Proliferation of cells & $1.19 \times 10^{-42}$ & Increased & 3.075 \\
Necrosis & $7.76 \times 10^{-36}$ & & -1.309 \\
Cell death & $2.45 \times 10^{-35}$ & & -1.146 \\
Apoptosis & $2.86 \times 10^{-34}$ & & -1.598 \\
Cell movement & $1.74 \times 10^{-28}$ & Increased & 3.756 \\
Migration of cells & $2.78 \times 10^{-28}$ & Increased & 3.179 \\
Metabolism of protein & $4.61 \times 10^{-28}$ & Increased & 2.429 \\
Proliferation of fibroblasts & $6.11 \times 10^{-22}$ & Increased & 2.54 \\
Invasion of cells & $1.96 \times 10^{-20}$ & Increased & 2.798 \\
Proliferation of fibroblast cell lines & $4.35 \times 10^{-19}$ & Increased & 2.526 \\
Proliferation of connective tissue cells & $2.36 \times 10^{-18}$ & Increased & 3.652 \\
Migration of connective tissue cells & $1.32 \times 10^{-16}$ & Increased & 2.843 \\
Cell movement of connective tissue cells & $2.77 \times 10^{-16}$ & Increased & 3.032 \\
Migration of fibroblasts & $7.95 \times 10^{-16}$ & Increased & 2.253 \\
Cell movement of fibroblasts & $5.39 \times 10^{-15}$ & Increased & 2.57 \\
Cell spreading & $1.08 \times 10^{-13}$ & Increased & 2.297 \\
Adhesion of connective tissue cells & $2.20 \times 10^{-10}$ & Increased & 2.849 \\
Attachment of cells & $1.65 \times 10^{-08}$ & Increased & 2.557 \\
Chemotaxis & $1.64 \times 10^{-06}$ & Increased & 2.317 \\
\hline
\end{tabular}

Interestingly, most $\mathrm{OPN}^{+} \mathrm{GFP}^{+}$fibroblasts had an activated phenotype with high FSC and SSC (Figure 6B).

We also confirmed the expression of OPN in bleomycintreated $\mathrm{GFP}^{+}$fibroblasts by immunofluorescence staining in vitro (Figure $6 \mathrm{D}$ ) and in vivo (Figure 6E). OPN was detected in the cytoplasm around the nucleus, probably associated with the endoplasmic reticulum and intracellular vesicles (Figure 6D). In vivo, $\mathrm{OPN}^{+}$rounded leukocytes were detected in the alveolar air spaces, possibly representing alveolar macrophages. ${ }^{42} \mathrm{OPN}^{+} \mathrm{GFP}^{+}$fibroblasts existed at the boundaries between the alveolar air spaces and the fibrotic region where $\mathrm{GFP}^{+}$fibroblasts clustered (Figure 6E). In addition, some $\mathrm{OPN}^{+} \mathrm{GFP}^{+}$fibroblasts were detected adjacent to epithelium-denuded alveoli (Figure 6E). Some but not all $\mathrm{OPN}^{+} \mathrm{GFP}^{+}$fibroblasts coexpressed $\alpha$ SMA, whereas $\mathrm{GFP}^{+}$fibroblasts clustering in fibrotic regions where the interstitium was thickened often expressed $\alpha$-SMA but not OPN (Figure $6 \mathrm{~F}$ ). $\mathrm{OPN}^{+} \mathrm{GFP}^{+}$ fibroblasts localized to places where alveolar structures still remained, but which appeared to be undergoing remodeling to form fibrotic regions (Figure 6F). Taken together, these results suggest that activated fibroblasts, especially those located at the edges of fibrotic regions, secrete OPN into the alveolar air spaces, resulting in an accumulation of OPN on the luminal surfaces of alveolar walls.

\section{Discussion}

The development of novel therapeutic strategies against pulmonary fibrosis requires a better understanding of fibroblast activation in the context of disease. We investigated the changes that occur in lung tissue cell populations, including fibroblast populations, after the induction of fibrosis. Unexpectedly, the number of fibroblasts present in the lungs did not increase, even at the peak of fibrosis, probably because proliferation and apoptosis were promoted concurrently in the fibrotic condition. Activated $\mathrm{GFP}^{+}$ fibroblasts possessed a characteristic phenotype consisting of enlarged cell size, increased intracellular organelle complexity, and up-regulation of genes involved in fibrogenesis. Of these genes, the OPN-encoding gene was the most highly up-regulated. OPN appeared to be secreted into alveolar spaces by activated fibroblasts located at the edges of fibrotic regions.

Fibrotic regions are considered to develop as a consequence of fibroblast migration, proliferation, and subsequent accumulation. Some in vitro studies suggest that activated fibroblasts acquire increased proliferative capacity. ${ }^{25,26,43}$ In addition, fibrosis and wound healing models have shown expansion of myofibroblasts in vivo. ${ }^{44,45}$ On the other hand, fibroblast proliferation has been shown to be inhibited by polymerized collagen, ${ }^{46}$ suggesting that proliferative regulation of fibroblasts in vivo may depend on the microenvironment. In our model, we observed BrdU uptake and clustering by $\mathrm{GFP}^{+}$fibroblasts. Although there is a possibility that repair of DNA damage could contribute in part to BrdU uptake, the increase in proliferative cells observed in Fucci mice is consistent with BrdU uptake by proliferating fibroblasts.

Comprehensive gene expression analysis revealed an up-regulation of proliferative genes but not apoptotic genes, whereas an increase of apoptotic fibroblasts was detected by flow cytometry. This difference may have arisen because SAGE was performed at day 14, rather than 
A

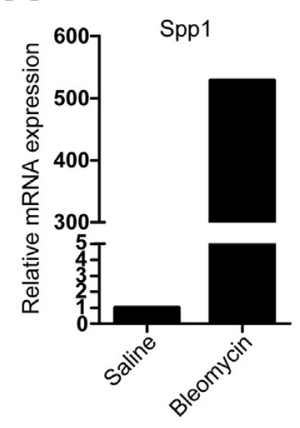

C

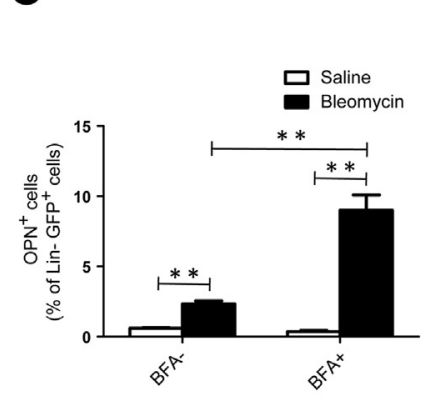

B Gate: Lin GFP $\mathrm{P}^{+}$
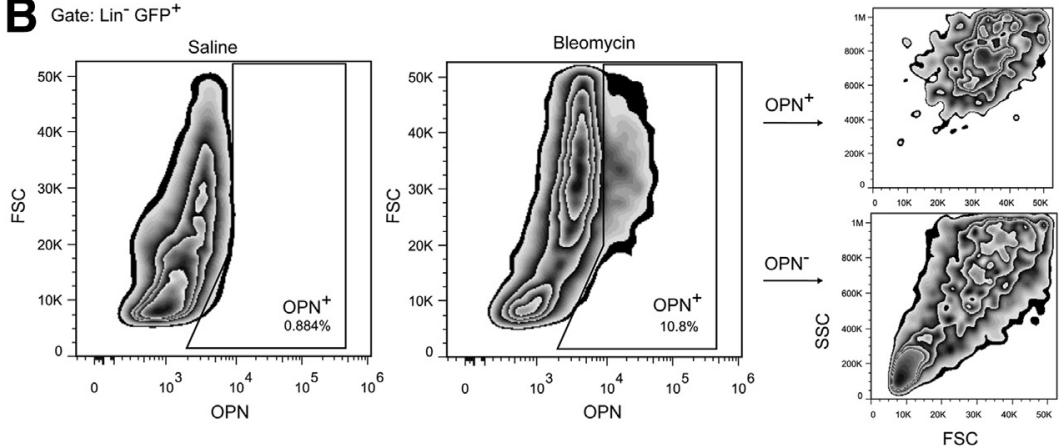

D

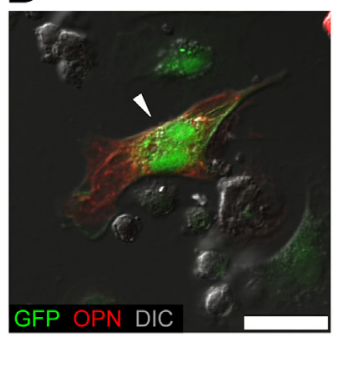

E

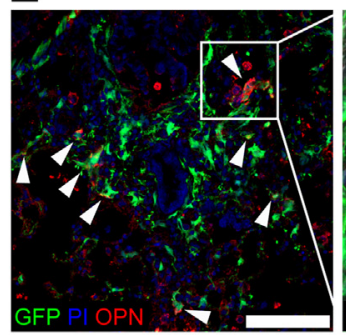

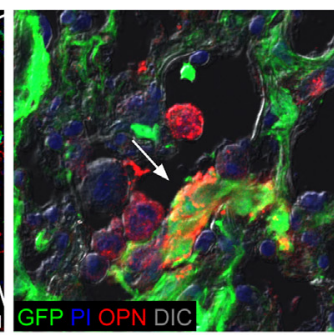

$\mathbf{F}$
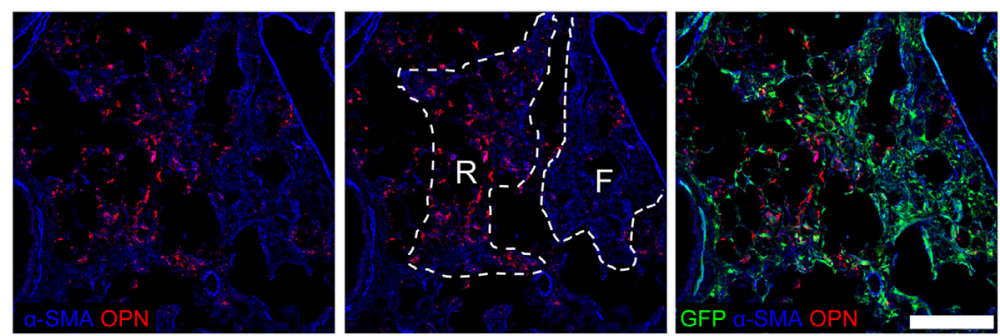

Figure $6 \quad \mathrm{OPN}$ is an activation marker of fibroblasts. A: $\mathrm{mRNA}$ isolated from sorted $\mathrm{Lin}^{-} \mathrm{GFP}^{+}$lung fibroblasts at 14 days after saline or bleomycin was analyzed by qPCR for Spp1. Template cDNA was pooled from the cells of three mice per group. B: Lung cells from Col1a2-GFP mice at 14 days after saline or bleomycin administration were cultured with BFA for 6 hours before staining for lineage markers and $\mathrm{OPN}$ (left). $\mathrm{OPN}^{+}$and $\mathrm{OPN}^{-} \mathrm{Lin}^{-} \mathrm{GFP}^{+}$fibroblasts from bleomycin-treated mice were plotted as FSC versus SSC (right). C: After 6 hour-culture of lung cells from saline or bleomycin-treated mice (day 14) with or without BFA, the proportion of $\mathrm{Lin}^{-} \mathrm{GFP}^{+}$cells that were $\mathrm{OPN}^{+}$was measured by flow cytometry. Data represent means $\pm \mathrm{SEM}(n=4) .{ }^{*} P<0.01$. D: Analysis by confocal microscopy of lung cells from Col1a2-GFP mice at 14 days after bleomycin administration. Cells were cultured in vitro with BFA for 6 hours before staining for $0 \mathrm{PNN}^{\text {(red). } 0 \mathrm{PN}{ }^{+} \mathrm{GFP}}{ }^{+}$cells are indicated by an arrowhead. E: Whole lungs from Col1a2-GFP mice at 14 days after bleomycin administration were cultured for 6 hours with BFA before sections were prepared and stained for OPN (red) and PI (blue). $\mathrm{OPN}^{+} \mathrm{GFP}^{+}$cells are indicated by arrowheads (left). The boxed region is shown at higher magnification at the right, highlighting an $\mathrm{OPN}^{+} \mathrm{GFP}^{+}$fibroblast (arrow) in an epithelium-denuded alveolus. F: Representative lung section from a Col1a2-GFP mouse at 14 days after bleomycin treatment, stained for $\alpha$-SMA (blue) and OPN (red). Scale bars: $25 \mu \mathrm{m}$ (D); $100 \mu \mathrm{m}$ (E); $200 \mu \mathrm{m}$ (F). F, fibrotic region; R, site of remodeling.

at day 7, when the peak of fibroblast apoptosis was observed. Also, because the proportion of apoptotic fibroblasts was very low (approximately $2 \%$ ), the gene expression of apoptotic fibroblasts might have been negated by that of nonapoptotic fibroblasts. In such a case, the expansion of the population of $\mathrm{GFP}^{+}$fibroblasts revealed by their BrdU uptake might not have been sufficient to surpass the rate of cell death by apoptosis. Furthermore, long-term BrdU-uptake experiments revealed that fibroblasts can form fibrotic clusters without massive proliferation. These findings suggest that an absolute increase in fibroblast numbers is not necessarily critical to the pathogenesis of pulmonary fibrosis. Rather, it is fibroblast accumulation in clusters resulting from cell migration that is likely to be most important to the progression of fibrogenesis.

Immunohistochemical examination of fibrotic lungs revealed a massive increase in the number of $\mathrm{GFP}^{+}$fibroblast clusters in fibrotic regions. However, we do not believe that the increased density of $\mathrm{GFP}^{+}$fibroblasts that was observed with immunohistochemistry contradicts the flowcytometric data showing that $\mathrm{GFP}^{+}$fibroblast numbers did not increase after bleomycin treatment. First, determining the proliferation of lung fibroblasts by histology is difficult, because fibrotic lung sections are filled with stroma (unlike normal lung sections, in which most of the area is made up of alveolar air spaces). Quantification of changes in tissue cell populations by flow cytometry after complete 
digestion of whole lungs avoids such limitations. Second, in epithelium-denuded alveoli, fibroblasts encroach on the alveolar air space and there they secrete ECM components, resulting in coalescence of the alveolar walls. ${ }^{47,48}$ Thus, the $\mathrm{GFP}^{+}$clusters observed in fibrotic regions are likely to be the result of fibroblast migration from surrounding alveolar walls into the alveolar air spaces. The up-regulation of genes associated with cell migration in $\mathrm{GFP}^{+}$fibroblasts supports this theory.

With the present study, we have identified OPN as an activation marker of lung fibroblasts during fibrosis. OPN is a matricellular protein that is implicated in various diseases, but that plays a different functional role from classical ECM proteins such as collagen or fibronectin. ${ }^{49}$ Mori et $\mathrm{al}^{50}$ found that knockdown of OPN decreased granulation tissue formation and scarring after skin injuries. Macrophage or mast cell-derived platelet-derived growth factor (PDGF) at the site of inflammation induced OPN expression in skin fibroblasts. Lenga et $\mathrm{al}^{51}$ demonstrated that OPN is required for myofibroblast differentiation and activity in cardiac and skin fibroblasts. Macrophages, T cells, and epithelial cells are known sources of OPN in lung fibrosis. Although it has been reported previously that IL-1 $\beta$ induces OPN expression in lung fibroblasts in vitro, ${ }^{52}$ the present study provides clear in vivo confirmation of OPN expression in lung fibroblasts during bleomycin-induced fibrosis. Other studies have suggested that epithelial cells, rather than fibroblasts, are the tissue cell source of OPN in pulmonary fibrosis. ${ }^{35,42}$ A possible explanation for this discrepancy is that we treated the cells with BFA, and detection of the OPN protein in $\mathrm{GFP}^{+}$fibroblasts was greatly enhanced after BFA treatment (Figure 6C). Nevertheless, the relative contribution of various tissue cell populations, including fibroblasts, as sources of OPN in pulmonary fibrosis remains to be determined.

The finding that the OPN gene Sppl was highly upregulated in $\mathrm{GFP}^{+}$fibroblasts after bleomycin treatment strongly suggests that OPN is involved in the pathogenesis of bleomycin-induced fibrosis. Previous studies have demonstrated that OPN enhances migration, invasion, and proliferation of lung fibroblasts. ${ }^{35,53}$ Because OPN was abundant in alveolar air spaces, especially those near fibrotic regions, we suspect the involvement of OPN in the process of fibroblast migration to alveolar air spaces and in the formation of fibrotic foci through the coalescence of alveolar walls with ECM. In OPN-null mice, altered formation of fibrotic regions is observed, characterized by dilated distal air spaces. ${ }^{42}$ Because the OPN gene SPP1 is also one of the most highly up-regulated genes in human idiopathic pulmonary fibrosis, ${ }^{35}$ understanding the role and mechanism action of OPN in the pathogenesis of fibrosis is likely to contribute to the development of novel therapies for this disease.

The comprehensive gene expression profile of freshly isolated fibroblasts suggested that activated fibroblasts became proliferative, resistant to cell death, mobile, and invasive. GO term enrichment demonstrated a role for these cells in ECM depositions, and flow cytometry and immunohistochemistry revealed expression of $\alpha$-SMA in some $\mathrm{GFP}^{+}$fibroblasts. These findings suggest that, after bleomycin treatment, some $\mathrm{GFP}^{+}$resident fibroblasts differentiate into myofibroblasts and play a critical role in fibrogenesis. However, because the possibility cannot be excluded that other cell types such as epithelial cells acquire GFP expression and a fibroblast phenotype after bleomycin treatment, the findings in the present study should be confirmed by strict lineage tracing of fibroblasts. We demonstrated that $\mathrm{GFP}^{+}$fibroblasts in the lungs were not supplied from the circulation. In a study using the same Colla2-GFP reporter mice, Higashiyama et $\mathrm{al}^{54}$ found that limited but significant number of $\mathrm{CD} 45^{+}$collagen type I-positive cells were recruited to skin in bleomycin-induced skin fibrosis. A possible explanation for the discrepancy between the present study and previous studies of fibrocytes is that we used parabiosis instead of bone marrow transplantation. Our present results clearly showed that circulating mesenchymal cells do not contribute significantly to fibroblast population in the lungs, and most of the fibroblasts in fibrotic regions are residential.

Interestingly, the localization of $\alpha$-SMA-expressing fibroblasts and OPN-expressing fibroblasts differed. $\alpha$ SMA-expressing fibroblasts were prominent within fibroblast clusters, whereas OPN-expressing fibroblasts were commonly located at the boundary of fibrotic regions and alveolar spaces. Thus, OPN expression and $\alpha$-SMA expression may represent different stages of fibrogenesis. Currently, most fibrosis studies rely on $\alpha$-SMA as a unique marker for myofibroblasts, based on the premise that myofibroblasts are the most important cell population in fibrogenesis. Given the various biological functions that OPN contributes to fibrogenesis, our findings suggest that $\mathrm{OPN}^{+}$collagen type I-producing fibroblasts represent a novel population of fibroblasts that play an important role in fibrogenesis, a role distinct from that of myofibroblasts.

In conclusion, we have revealed in vivo properties of fibroblasts during bleomycin-induced pulmonary fibrosis, showing their profibrotic signatures without changes in number. From the gene expression profile, the gene encoding OPN was identified as the most highly expressed gene in fibroblasts, with distinct localizations that are different from those of myofibroblasts, suggesting potential use of OPN as a novel activation marker of fibroblasts. Taken together, these findings provide useful insights toward further elucidation of the cellular and molecular mechanisms of pulmonary fibrosis.

\section{Acknowledgments}

We thank Dr. Atsushi Miyawaki and the RIKEN BioResource Center cell bank for supplying FucciG1-\#639 and FucciS/G2/M-\#474 mice. 


\section{Supplemental Data}

Supplemental material for this article can be found at http://dx.doi.org/10.1016/j.ajpath.2013.06.005.

\section{References}

1. Wynn TA, Ramalingam TR: Mechanisms of fibrosis: therapeutic translation for fibrotic disease. Nat Med 2012, 18:1028-1040

2. King TE Jr, Pardo A, Selman M: Idiopathic pulmonary fibrosis. Lancet 2011, 378:1949-1961

3. Wynn TA: Cellular and molecular mechanisms of fibrosis. J Pathol 2008, 214:199-210

4. Hinz B, Phan SH, Thannickal VJ, Galli A, Bochaton-Piallat ML, Gabbiani G: The myofibroblast. Am J Pathol 2007, 170:1807-1816

5. Wynn TA: Integrating mechanisms of pulmonary fibrosis. J Exp Med 2011, 208:1339-1350

6. Noble PW, Barkauskas CE, Jiang D: Pulmonary fibrosis: patterns and perpetrators. J Clin Invest 2012, 122:2756-2762

7. Kim KK, Wei Y, Szekeres C, Kugler MC, Wolters PJ, Hill ML, Frank JA, Brumwell AN, Wheeler SE, Kreidberg JA, Chapman HA: Epithelial cell alpha3beta1 integrin links beta-catenin and Smad signaling to promote myofibroblast formation and pulmonary fibrosis. J Clin Invest 2009, 119:213-224

8. Tanjore H, Xu XC, Polosukhin VV, Degryse AL, Li B, Han W, Sherrill TP, Plieth D, Neilson EG, Blackwell TS, Lawson WE: Contribution of epithelial-derived fibroblasts to bleomycin-induced lung fibrosis. Am J Respir Crit Care Med 2009, 180:657-665

9. Hoyles RK, Derrett-Smith EC, Khan K, Shiwen X, Howat SL, Wells AU, Abraham DJ, Denton CP: An essential role for resident fibroblasts in experimental lung fibrosis is defined by lineage-specific deletion of high-affinity type II transforming growth factor receptor. Am J Respir Crit Care Med 2010, 183:249-261

10. Rock JR, Barkauskas CE, Cronce MJ, Xue Y, Harris JR, Liang J, Noble PW, Hogan BLM: Multiple stromal populations contribute to pulmonary fibrosis without evidence for epithelial to mesenchymal transition. Proc Natl Acad Sci USA 2011, 108:E1475-E1483

11. Lin SL, Kisseleva T, Brenner DA, Duffield JS: Pericytes and perivascular fibroblasts are the primary source of collagen-producing cells in obstructive fibrosis of the kidney. Am J Pathol 2008, 173: $1617-1627$

12. Göritz C, Dias DO, Tomilin N, Barbacid M, Shupliakov O, Frisén J: A pericyte origin of spinal cord scar tissue. Science 2011, 333: 238-242

13. Herzog EL, Brody AR, Colby TV, Mason R, Williams MC: Knowns and unknowns of the alveolus. Proc Am Thorac Soc 2008, 5:778-782

14. Kunz-Schughart LA, Wenninger S, Neumeier T, Seidl P, Knuechel R: Three-dimensional tissue structure affects sensitivity of fibroblasts to TGF-beta 1. Am J Physiol Cell Physiol 2003, 284:C209-C219

15. De Val S, Ponticos M, Antoniv TT, Wells DJ, Abraham D, Partridge T, Bou-Gharios G: Identification of the key regions within the mouse pro-alpha 2(I) collagen gene far-upstream enhancer. J Biol Chem 2001, 277:9286-9292

16. Higashiyama R, Moro T, Nakao S, Mikami K, Fukumitsu H, Ueda Y, Ikeda K, Adachi E, Bou-Gharios G, Okazaki I, Inagaki Y: Negligible contribution of bone marrow-derived cells to collagen production during hepatic fibrogenesis in mice. Gastroenterology 2009, 137: $1459-1466$

17. Tomura M, Mori YS, Watanabe R, Tanaka M, Miyawaki A, Kanagawa O: Time-lapse observation of cellular function with fluorescent probe reveals novel CTL-target cell interactions. Int Immunol 2009, 21:1145-1150

18. Foster WM, Walters DM, Longphre M, Macri K, Miller LM: Methodology for the measurement of mucociliary function in the mouse by scintigraphy. J Appl Physiol 2001, 90:1111-1117
19. Shimbori C, Shiota N, Okunishi H: Involvement of leukotrienes in the pathogenesis of silica-induced pulmonary fibrosis in mice [Erratum appeared in Exp Lung Res 2010, 36:440]. Exp Lung Res 2010, 36: 292-301

20. Fujita M, Shannon JM, Irvin CG, Fagan KA, Cool C, Augustin A, Mason RJ: Overexpression of tumor necrosis factor-alpha produces an increase in lung volumes and pulmonary hypertension. Am J Physiol Lung Cell Mol Physiol 2001, 280:L39-L49

21. Huang DW, Sherman BT, Lempicki RA: Systematic and integrative analysis of large gene lists using DAVID bioinformatics resources. Nat Protoc 2008, 4:44-57

22. Kapanci Y, Ribaux C, Chaponnier C, Gabbiani G: Cytoskeletal features of alveolar myofibroblasts and pericytes in normal human and rat lung. J Histochem Cytochem 1992, 40:1955-1963

23. Fukuda Y, Ferrans VJ, Schoenberger CI, Rennard SI, Crystal RG: Patterns of pulmonary structural remodeling after experimental paraquat toxicity. The morphogenesis of intraalveolar fibrosis. Am J Pathol 1985, 118:452-475

24. Kawamoto M, Fukuda Y: Cell proliferation during the process of bleomycin-induced pulmonary fibrosis in rats. Acta Pathol Jpn 1990, 40:227-238

25. Moseley PL, Hemken C, Hunninghake GW: Augmentation of fibroblast proliferation by bleomycin. J Clin Invest 1986, 78:1150-1154

26. Mio T, Nagai S, Kitaichi M, Kawatani A, Izumi T: Proliferative characteristics of fibroblast lines derived from open lung biopsy specimens of patients with IPF (UIP). Chest 1992, 102:832-837

27. Messier EM, Mason RJ, Kosmider B: Efficient and rapid isolation and purification of mouse alveolar type II epithelial cells. Exp Lung Res 2012, 38:363-373

28. Mouratis MA, Aidinis V: Modeling pulmonary fibrosis with bleomycin. Curr Opin Pulm Med 2011, 17:355-361

29. Zhang K, Rekhter MD, Gordon D, Phan SH: Myofibroblasts and their role in lung collagen gene expression during pulmonary fibrosis. A combined immunohistochemical and in situ hybridization study. Am J Pathol 1994, 145:114-125

30. Takemoto K: Spatio-temporal activation of caspase revealed by indicator that is insensitive to environmental effects. J Cell Biol 2003, 160:235-243

31. Nagai T, Miyawaki A: A high-throughput method for development of FRET-based indicators for proteolysis. Biochem Biophys Res Commun 2004, 319:72-77

32. Sakaue-Sawano A, Kurokawa H, Morimura T, Hanyu A, Hama H, Osawa H, Kashiwagi S, Fukami K, Miyata T, Miyoshi H, Imamura T, Ogawa M, Masai H, Miyawaki A: Visualizing spatiotemporal dynamics of multicellular cell-cycle progression. Cell 2008, 132:487-498

33. Phillips RJ, Burdick MD, Hong K, Lutz MA, Murray LA, Xue YY, Belperio JA, Keane MP, Strieter RM: Circulating fibrocytes traffic to the lungs in response to CXCL12 and mediate fibrosis. J Clin Invest 2004, 114:438-446

34. Hashimoto N: Bone marrow-derived progenitor cells in pulmonary fibrosis. J Clin Invest 2004, 113:243-252

35. Pardo A, Gibson K, Cisneros J, Richards TJ, Yang Y, Becerril C, Yousem S, Herrera I, Ruiz V, Selman M, Kaminski N: Up-regulation and profibrotic role of osteopontin in human idiopathic pulmonary fibrosis. PLoS Med 2005, 2:e251

36. Kaminski N, Allard JD, Pittet JF, Zuo F, Griffiths MJ, Morris D, Huang X, Sheppard D, Heller RA: Global analysis of gene expression in pulmonary fibrosis reveals distinct programs regulating lung inflammation and fibrosis. Proc Natl Acad Sci USA 2000, 97: $1778-1783$

37. Kass DJ, Yu G, Loh KS, Savir A, Borczuk A, Kahloon R, JuanGuardela B, Deiuliis G, Tedrow J, Choi J, Richards T, Kaminski N, Greenberg SM: Cytokine-like factor 1 gene expression is enriched in idiopathic pulmonary fibrosis and drives the accumulation of CD4+ T cells in murine lungs. Am J Pathol 2012, 180:1963-1978

38. Oikonomou N, Thanasopoulou A, Tzouvelekis A, Harokopos V, Paparountas T, Nikitopoulou I, Witke W, Karameris A, Kotanidou A, 
Bouros D, Aidinis V: Gelsolin expression is necessary for the development of modelled pulmonary inflammation and fibrosis. Thorax 2009, 64:467-475

39. Zhou Y, Koli K, Hagood JS, Miao M, Mavalli M, Rifkin DB, Murphy-Ullrich JE: Latent transforming growth factor- $\beta$-binding protein-4 regulates transforming growth factor- $\beta 1$ bioavailability for activation by fibrogenic lung fibroblasts in response to bleomycin. Am J Pathol 2009, 174:21-33

40. Ishii Y: Gefitinib prevents bleomycin-induced lung fibrosis in mice. Am J Respir Crit Care Med 2006, 174:550-556

41. Wilson MS, Madala SK, Ramalingam TR, Gochuico BR, Rosas IO, Cheever AW, Wynn TA: Bleomycin and IL-1-mediated pulmonary fibrosis is IL-17A dependent. J Exp Med 2010, 207:535-552

42. Berman JS: Altered bleomycin-induced lung fibrosis in osteopontindeficient mice. Am J Physiol Lung Cell Mol Physiol 2004, 286: L1311-L1318

43. Ramos C, Montaño M, García-Alvarez J, Ruiz V, Uhal BD, Selman M, Pardo A: Fibroblasts from idiopathic pulmonary fibrosis and normal lungs differ in growth rate, apoptosis, and tissue inhibitor of metalloproteinases expression. Am J Respir Cell Mol Biol 2001, 24:591-598

44. Humphreys BD, Lin SL, Kobayashi A, Hudson TE, Nowlin BT, Bonventre JV, Valerius MT, McMahon AP, Duffield JS: Fate tracing reveals the pericyte and not epithelial origin of myofibroblasts in kidney fibrosis. Am J Pathol 2010, 176:85-97

45. Virag JI, Murry CE: Myofibroblast and endothelial cell proliferation during murine myocardial infarct repair. Am J Pathol 2003, 163: 2433-2440

46. Xia H, Nho R, Kleidon J, Kahm J, Henke CA: Polymerized collagen inhibits fibroblast proliferation via a mechanism involving the formation of a betal integrin-protein phosphatase 2A-tuberous sclerosis complex 2 complex that suppresses S6K1 activity. J Biol Chem 2008, 283:20350-20360

47. Noble PW: Back to the future: historical perspective on the pathogenesis of idiopathic pulmonary fibrosis. Am J Respir Cell Mol Biol 2005, 33:113-120

48. Myers J, Katzenstein A: Epithelial necrosis and alveolar collapse in the pathogenesis of usual interstitial pneumonia. Chest 1988, 94 : 1309-1311

49. Uede T: Osteopontin, intrinsic tissue regulator of intractable inflammatory diseases. Pathol Int 2011, 61:265-280

50. Mori R, Shaw TJ, Martin P: Molecular mechanisms linking wound inflammation and fibrosis: knockdown of osteopontin leads to rapid repair and reduced scarring. J Exp Med 2008, 205:43-51

51. Lenga Y, Koh A, Perera AS, McCulloch CA, Sodek J, Zohar R: Osteopontin expression is required for myofibroblast differentiation. Circ Res 2008, 102:319-327

52. Serlin DM, Kuang PP, Subramanian M, O'Regan A, Li X, Berman JS, Goldstein RH: Interleukin- $1 \beta$ induces osteopontin expression in pulmonary fibroblasts. J Cell Biochem 2006, 97:519-529

53. Anwar A, Li M, Frid MG, Kumar B, Gerasimovskaya EV, Riddle SR, McKeon BA, Thukaram R, Meyrick BO, Fini MA, Stenmark KR: Osteopontin is an endogenous modulator of the constitutively activated phenotype of pulmonary adventitial fibroblasts in hypoxic pulmonary hypertension. Am J Physiol Lung Cell Mol Physiol 2012, 303:L1-L11

54. Higashiyama R, Nakao S, Shibusawa $\mathrm{Y}$, Ishikawa $\mathrm{O}$, Moro $\mathrm{T}$, Mikami K, Fukumitsu H, Ueda Y, Minakawa K, Tabata Y, BouGharios G, Inagaki Y: Differential contribution of dermal resident and bone marrow-derived cells to collagen production during wound healing and fibrogenesis in mice. J Invest Dermatol 2011, 131: $529-536$ 